\title{
Indirect Evaporative Cooling for Buildings: A Comprehensive Patents Review
}

\author{
Ramy H. Mohammed ${ }^{\mathrm{a}, \mathrm{b}}$, Mohamed El-Morsi ${ }^{\mathrm{a}}$, Omar Abdelaziz ${ }^{\mathrm{a}, *}$ \\ ${ }^{\text {a }}$ Department of Mechanical Engineering, The American University in Cairo, AUC Avenue, New Cairo 11835, Egypt. \\ ${ }^{\mathrm{b}}$ Department of Mechanical Power Engineering, Zagazig University, Zagazig 44519, Egypt. \\ * Corresponding author: Email: omar_abdelaziz@aucegypt.edu
}

\begin{abstract}
Indirect evaporative cooling (IEC) is an eco-friendly technology that has the potential to reduce energy consumption by 4 times compared with conventional air conditioners (AC). However, IEC has not been widely used due to operational limitations in humid environments and water availability in arid environments. Many patents related to IEC have been granted in the past decades, aiming to make breakthrough innovations. This article reviews and discusses published patents in a chronological order and presents the different configurations of IEC devices. It presents the standards and evaluation parameters utilized to characterize the performance of IEC devices. Additionally, the current research gaps are identified, and the outlook of this technology is highlighted. This review shows that the convective air heat transfer on the dry side of the IEC heat exchangers is generally the limiting factor in how small IEC devices can be constructed. One of the main factors that negatively affect the cooling capacity of IEC technology is the non-uniform wettability of the wet channel surface. With the recent research and development, the share of IEC technology in the AC market will increase noticeably in the next decades, aiming to reduce the energy consumption and the carbon footprint in the building sector.
\end{abstract}

Keywords: Indirect evaporative cooler; Heat exchanger; Performance; Dewpoint; Optimization. 


\section{Nomenclature}

$c_{p}$

COP

ECER

$h$

$\dot{Q}_{c c}$

$t$

$\dot{V}_{w}$

$\dot{V}$

Greek symbols

$\omega$

$\varepsilon_{d p}$

$\varepsilon_{w b}$

$\rho$

\section{Subscripts}

$d b$

$d p$

in

out

$p$

room

S

$w$

$w b$

\section{Abbreviations}

3D

AC

ANSI

ASHRAE

DEC

D-IEC

DW

EC

GSO

HVAC

HX

IEC

IT

M-cycle

PV

R-IEC

$\mathrm{SCC}$

$\mathrm{VC}$ specific heat at constant pressure, J/kg.K

coefficient of performance

evaporative cooler efficiency ratio, -

specific enthalpy, $\mathrm{J} / \mathrm{kg}$

cooling capacity, $\mathrm{kW}$

temperature, ${ }^{\circ} \mathrm{C}$

water evaporation rate, $\mathrm{m}^{3}$ of water/s

air flow rate, $\mathrm{m}^{3}$ of air/s

humidity ratio, $\mathrm{kg}$ of water/ $\mathrm{kg}$ of dry air

dew point effectiveness, -

wet-bulb effectiveness, -

density, $\mathrm{kg} / \mathrm{m}^{3}$

Dry bulb

dew point

inlet

outlet

primary air

Room conditions

secondary

Water

Wet bulb

three dimensional

air conditioners/conditioning

American national standards institute

American society of heating, refrigerating and air-conditioning engineers

direct evaporative cooling

dew-point indirect evaporative cooling

desiccant wheel

evaporative cooling

Gulf cooperation council standardization organization

heating, ventilation, and air conditioning

heat exchanger

indirect evaporative cooling

Information Technology

Maisotsenko cycle

photovoltaic

regenerative indirect evaporative cooling

standards council of Canada

vapor compression 


\section{Introduction}

In 2010, the global electricity generation was estimated to be $20 \mathrm{TWh}$, of which the fossil fuel and nuclear share was $81 \%$. This capacity is expected to grow by $70 \%$ in 2035 [1]. This value grew to $23 \mathrm{TWh}$ while the share of fossil fuel and nuclear contribution was reduced to $75.6 \%$ due to the increased penetration of renewable energy in 2019 [2]. Air conditioning (AC) systems and fans consume roughly $20 \%$ of the electricity consumed in buildings to maintain thermal comfort $[3,4]$. $\mathrm{CO}_{2}$ emissions from the operation of buildings have increased to $38 \%$ of total global energy-related $\mathrm{CO}_{2}$ emissions [5]. AC is becoming increasingly essential, particularly for commercial and residential buildings. During the hottest summer period when AC is in full operation, countries like China and Saudi Arabia experience high power overloads, leading to electric grid instabilities [6]. Therefore, the continuously rising demand for AC puts heavy stress on the electrical grid in many countries and increases the carbon emissions remarkably [6]. The average coefficient of performance (COP) (i.e., energy efficiency) of AC available on the market is about one-third of the best available technology [3]. Without introducing highly efficient AC technologies to the market, energy demand for space cooling will increase three folds by 2050 [3].

Increasing the efficiency of AC systems and reducing their environmental footprint are among the main challenges to reduce the reliance on fossil fuels and achieve the sustainable development goals (especially goal No. 7: affordable and clean energy and No. 13: climate action) [7,8]. Conventional vapor compression (VC) technologies dominate the Heating, Ventilation, and Air Conditioning (HVAC) systems $[9,10]$. In VC systems, the latent cooling load is handled by cooling the air below its dew-point temperature to condense the water vapor. To meet the required indoor conditions, the dehumidified air is sometimes reheated electrically [11] which further reduces the overall efficiency of conventional VC systems. To avoid the shortcomings of the VC systems, efficient, low-cost, and eco-friendly AC systems are required. One of the efficient cooling methods is the evaporative cooling (EC) [12,13]. The main advantages of EC over conventional VC systems are the use of water instead of chemicals or refrigerants, quiet operation, low installation and maintenance cost, and lower energy consumption [14-16]. With proper modifications, EC technology could be implemented in different applications, besides space cooling, such as water desalination $[17,18]$ and agricultural storage $[19,20]$.

EC consumes about one-quarter of the energy used in conventional systems [21]. EC devices could be classified into direct evaporator cooler (DEC) and indirect evaporator cooler (IEC). IEC has many advantages over DEC, as discussed in the following section. Over the past years, several research studies focused on different HX designs of IEC systems [22,23] and their material [24,25] to enhance the heat and mass transfer processes and improve the overall efficiency. Recently 
published review papers focused on research papers that discussed different system configurations and optimization [26], hybrid systems and equipment [27], mathematical models of different arrangements [28,29], and performance assessment of IEC systems [13]. Table 1 lists some recently published papers in this research direction. It is shown that each review paper discusses different aspects related to EC. It can be concluded from the table that reviewing the academic articles related to EC was covered and discussed in literature.

Table 1 Overview of previous review papers related to EC

\begin{tabular}{|c|c|l|}
\hline Reference & Overall focus & \multicolumn{1}{c|}{ Detailed focus } \\
\hline$[30,31]$ & EC & DEC and IEC as a component in hybrid systems. \\
\hline$[32]$ & EC & Hybrid dehumidification systems for hot and humid regions. \\
\hline$[28]$ & EC & $\begin{array}{l}\text { Techno-economic assessment, environmental evaluation, and working } \\
\text { strategies of IEC and DEC. }\end{array}$ \\
\hline$[33]$ & M-cycle & Characteristics, hybrid cycles, and working principles. \\
\hline$[29]$ & EC & $\begin{array}{l}\text { Adding different dehumidification sections to enhance the overall } \\
\text { performance of EC. }\end{array}$ \\
\hline$[13]$ & IEC & $\begin{array}{l}\text { Governing equations, combined systems, water spray devices, and } \\
\text { optimization. }\end{array}$ \\
\hline
\end{tabular}

Published patents present innovative ideas supporting and enhancing technological development in the patent's topic. Thus, reviewing and discussing the IEC patents are important to identify the current technology gaps. To the best of our knowledge, there is no recent review paper for granted patents related to IEC systems and their performance. Therefore, the main goal of the present patent review is to comprehensively summarize and discuss technological advances presented in published patents related to IEC devices. The current work demonstrates the innovative patented designs and configurations of IEC systems that could be used in space cooling to reduce energy consumption and shift the peak electricity demand. The paper goes over performance evaluation standards and parameters used to assess the effectiveness of IEC devices. It also demonstrates different constructions of HXs used in IEC devices. Moreover, it presents the materials used in IEC devices and their advantages and disadvantages. Finally, it identifies the current technology gaps and suggests a roadmap for research and development for IEC technologies.

The present paper has five sections following the Introduction. Section 2 describes the main features of DEC and different types of IEC. Section 3 presents international standards and evaluation parameters used to assess the performance of IEC. The methodology of the present study is mentioned in Section 4. Reviewing published patents related to several aspects of IECs is presented in Section 5. Based on this section, research, technology, and development gaps are identified in Section 6. Finally, the conclusions are drawn and summarized in Section 7. 


\section{Evaporative cooling systems}

\subsection{Direct versus indirect evaporative cooling systems}

EC is an adiabatic process in which the sensible air temperature is reduced and compensated by latent heat gain. When EC is used in buildings, the cooling temperature depends on the ambient conditions (i.e., temperature and humidity) and water availability. According to the airstream directions, EC systems can be categorized into counter-flow and cross-flow types. Also, they could primarily be classified into direct or indirect processes, based on the contact between the process air and water, as illustrated in Fig. 1. In the direct evaporative cooling (DEC) system, air passes through a wet surface (cooling pad), where it cools and gains moisture, as shown in Fig. 1a. This process typically involves heat and mass transfer. The supply hot air exits the DEC as cold and humid air at constant wet-bulb temperature, where the change in air enthalpy is zero due to the use of the latent heat of evaporation (see Fig. 1b). Existing DEC systems are 70 to $95 \%$ effective in terms of the incoming air wet-bulb temperature [12] and are only suitable for hot and dry climates or in applications requiring simultaneous cooling and humidification. Additionally, DEC systems may result in the transmission of Legionella with airborne droplets, making it unsuitable for widespread commercialization. Indirect evaporative cooling (IEC) is an alternative evaporative cooling technology that avoids these drawbacks.

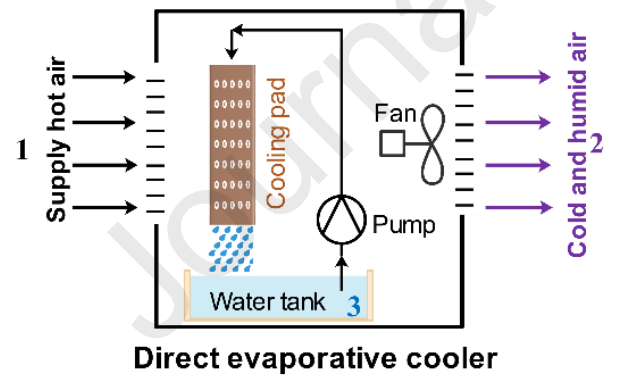

(a)

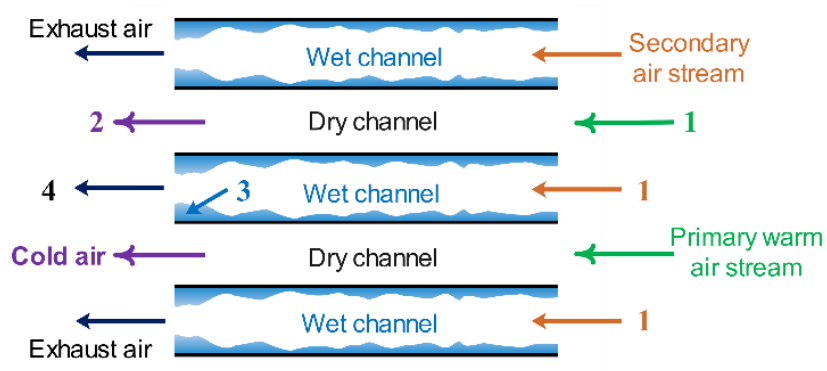

(c)

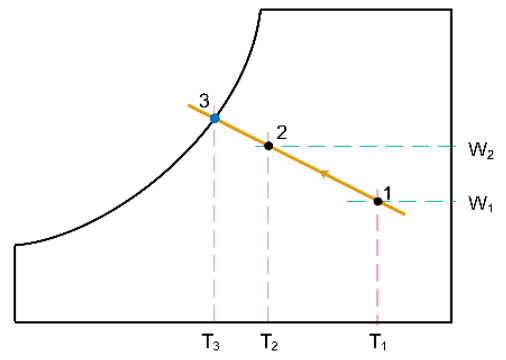

(b)

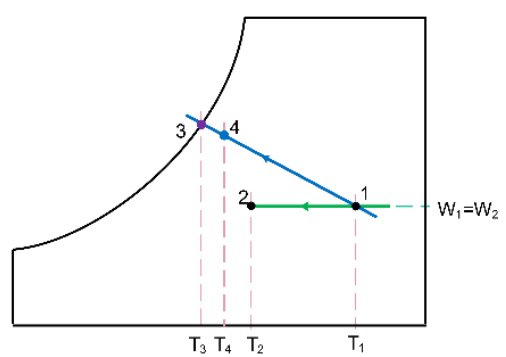

(d)

Fig. 1. Schematic drawings for DEC ( $a$ and $b)$ and IEC ( $c$ and $d)$.

In the IEC, the supply air does not come in contact with water, which is cooled evaporatively, thus eliminating the problems linked to the spread of airborne bacteria, as drawn in Fig. 1c. In IEC devices, the primary or product air passes through the dry channels of heat exchanger (HX) and the secondary or working air travels through the wet channels. The wet side absorbs heat from the dry 
side by evaporating water, thus cooling the dry side, while the water latent heat of vaporization is released to the air in the wet channel [34]. The primary air temperature on the dry channels decreases sensibly from point 1 to 2 , as shown in Fig. 1d. Subsequently, the IEC systems have the advantage of lowering the air temperature without adding moisture. Theoretically, the lowest temperature that primary air could reach is the water temperature [35]. However, practical systems are far from this ideal due to the limited HX effectiveness, making such systems less effective than DEC systems. Combined IEC and DEC systems have improved performance potential for cooling applications [36].

\subsection{Types of indirect evaporative cooling systems}

The IEC technology is considered feasible for climates with significant differences between dryand wet-bulb temperatures during the cooling season. IEC can generally be classified as conventional, dewpoint, regenerative, and Maisotsenko cycle (M-cycle) cooling systems. Conventional IEC systems have alternating wet and dry channels. In the dewpoint IEC (D-IEC), the primary air is cooled below its wet-bulb temperature. Pandelidis et al. [37] evaluated the performance of a counter-flow DIEC under summer conditions. Their system was able to dehumidify the process air by $1.8 \mathrm{~g} / \mathrm{kg}$ when the inlet conditions were $34^{\circ} \mathrm{C}$ and $50 \%$ RH. Regenerative IEC (R-IEC) is similar to the D-IEC system in which the primary outdoor air goes into two dry channels in parallel to be cooled close to its dewpoint temperature. At the exit, a portion of the primary cooled air is driven through the wet channels to exchange sensible and latent heat, as presented in Fig. 2 [38]. Based on the streams directions, parallel/counter-flow and crossflow R-IEC systems have been proposed and evaluated. The parallel/cross-flow in wet channels behaved better [27]. The main drawback of R-IEC is the reduced flow rate compared with conventional IEC because of splitting the primary air at the exit. R-IEC is considered a sustainable, environmentally friendly, and efficient option for cooling [39]. The M-cycle was proposed by Maisotsenko's team via Patent No. SU620745 [40] and Patent No. SU979796 [41]. Its working principle is similar to the dew-point and R-IEC, in which the wet channels were coated by capillary-porous material to provide efficient wetting, as shown in Fig. 3 [33]. This configuration requires that the intake of primary and secondary air be separated and allows the secondary air to be continuously cooled and transferred to the wet channel. The M-cycle configuration results in 10 to $30 \%$ higher effectiveness compared with R-IEC due to the improved heat exchange. However, this comes at the cost of complex flow pattern.

It can be inferred that the HX design and directions of the air streams in the IEC system have a significant impact on its effectiveness. Plate and tube HXs and heat pipes have been widely used in IEC [23]. Regarding the air stream direction in plate HX, the counter-flow provides more cooling effectiveness and more system compactness than the cross-flow arrangement [42]. Further improvement in the performance of the IEC system could be achieved through its integration with 
other systems, such as DEC device [43], desiccant wheel (DW) [44], conventional ACs [45], water desalination cycle [17], inverted Brayton cycle [46], and others.

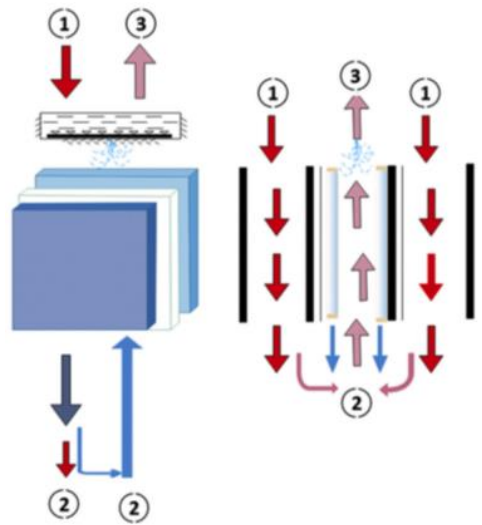

(a)

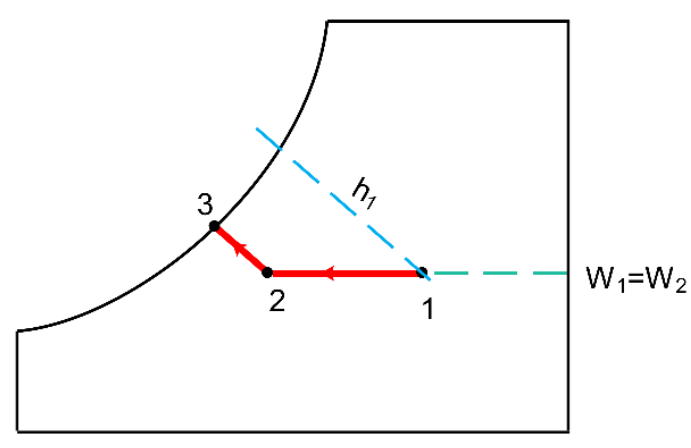

(b)

Fig. 2. R-IEC: (a) configuration and (b) psychrometric representation [27].

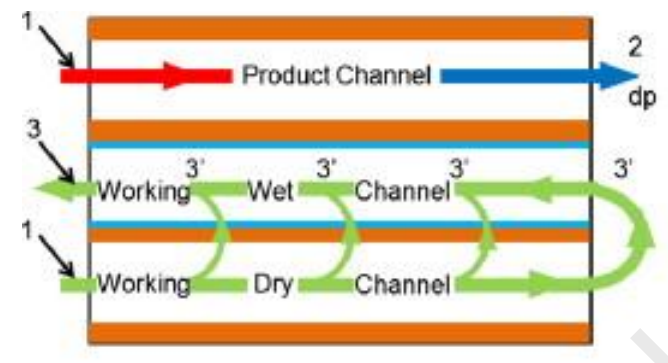

(a)

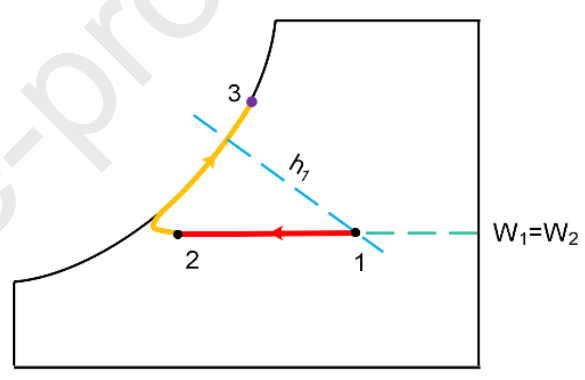

(b)

Fig. 3. M-cycle: (a) configuration and (b) psychrometric representation [47].

\section{Performance evaluation standards and parameters}

Several organizations have suggested different standards to evaluate the performance of IEC units. The most widely used test standard is the ANSI/ASHRAE 143-2015 standard: Method of test for rating indirect evaporative coolers [48]. This standard covers the test of IEC effectiveness at steady-state conditions. In the Gulf region, standard GSO 2115:2011 is utilized to evaluate the effectiveness and energy consumption of evaporative cooling units [49]. Standards Council of Canada (SCC) designed the standard C22.2 No.104-01 for testing the humidifiers [50]. China National Standards published the standard code GB/T 25860-2010 for testing and evaluating evaporative cooling systems [51]. Reviewing these standards and codes indicated that the performance of IEC systems could be represented by several characteristic parameters, including (1) pressure loss, (2) wet-bulb or dew-point effectiveness, (3) evaporative cooler efficiency ratio, (4) cooling capacity, (5) energy efficiency, and (6) water evaporation rate. These parameters are detailed as follows: 


\section{a. Pressure loss}

Pressure loss is a measurement of the static pressure drop of the primary and secondary air across the HX. Typically, this value ranges from 60-185 $\mathrm{Pa}$ and 100-500 $\mathrm{Pa}$ in the dry and wet channels, respectively [47].

\section{b. Wet-bulb effectiveness}

Wet-bulb effectiveness $\left(\varepsilon_{w b}\right)$ indicates the approaching of the outlet primary air temperature to its inlet wet-bulb temperature, and is formulated as [52]:

$$
\varepsilon_{w b}=\frac{t_{d b, \text { in }}-t_{d b, \text { out }}}{t_{d b, \text { in }}-t_{w b, \text { in }}}
$$

where $t_{d b}$ is the dry-bulb temperature and $t_{w b}$ is the wet-bulb temperature. Subscripts in and out refer to inlet and outlet primary air stream, respectively.

\section{c. Dew-point effectiveness}

Dew point effectiveness $\left(\varepsilon_{d p}\right)$ indicates the approaching of the outlet primary air temperature to its inlet dew-point temperature. It is calculated as [52]:

$$
\varepsilon_{d p}=\frac{t_{d b, \text { in }}-t_{d b, \text { out }}}{t_{d b, \text { in }}-t_{d p, \text { in }}}
$$

where $t_{d p}$ is the dew-point temperature of primary air.

\section{d. Evaporative cooler efficiency ratio}

Evaporative cooler efficiency ratio (ECER) is the ratio between the actual cooling delivered to the power consumed to drive the IEC. It is measured at the condition of intake air dry/wet bulb temperatures of $32.8 / 20.6^{\circ} \mathrm{C}$ and room air dry bulb temperature of $26.7^{\circ} \mathrm{C}$. This is formulated as [15]:

$$
\text { ECER }=\frac{\rho_{p} c_{p}\left[t_{\text {room }}-t_{d b, \text { out }}\right] \dot{V}_{p, o u t}}{\text { Power }}
$$

where $\rho_{p}$ is the density of primary air, $c_{p}$ is the specific heat at a constant pressure of primary air, and $\dot{V}_{p, o u t}$ is the volume flow rate of the primary air exiting the IEC.

\section{e. Cooling capacity}

The cooling capacity $\left(\dot{Q}_{c c}\right)$ is the change in air enthalpy across the dry channels of the IEC HX, and is written as [53]:

$$
\dot{Q}_{c c}=\rho_{p} \dot{V}_{p, \text { out }}\left(h_{p, \text { in }}-h_{p, \text { out }}\right)
$$


where $h_{p}$ is the enthalpy of primary air.

\section{f. Energy efficiency}

Energy efficiency, known as COP, is the ratio of the cooling capacity of the IEC device to the input power. This term can be mathematically written as [54]:

$$
\text { Energy efficiency }=\frac{\dot{Q}_{c c}}{\text { Power input }}
$$

\section{g. Water evaporation rate}

The water evaporation rate $\left(\dot{V}_{w}\right)$ of an IEC system depends on several operating parameters, such as the inlet air temperature/humidity, airflow rate, treated cooling load, and the system's cooling effectiveness. Theoretically, the water evaporation rate is equal to the volume flow rate of the moisture increase and is calculated as [54]:

$$
\dot{V}_{w}=\frac{\dot{V}_{s, \text { out }} \rho_{s}}{\rho_{w}}\left(\omega_{s, \text { out }}-\omega_{s, \text { in }}\right)
$$

where $\omega_{s}$ is the moisture content of secondary stream and $\rho_{w}$ is the water density.

\section{Methodology of the study}

Scientists, engineers, and innovators continued to publish patents related to IEC devices for HVAC applications over the last several decades in an effort to commercialize this energy efficient and environmentally friendly technology. Fig. 4 shows the cumulative number of published patents about IEC over the last twenty years [55]. The curve is plotted by using "indirect evaporative" as a search keyword in the title of the published patents in the Espacenet database [55]. The cumulative number of patents related to the IEC as a component used in HVAC systems reached 617 patents by the end of 2020, compared to 161 patents in 2010 (about 4 times increase in the last decade). This trend indicates that the IEC technology has received much interest due to its advantages, such as high efficiency and low running cost. 


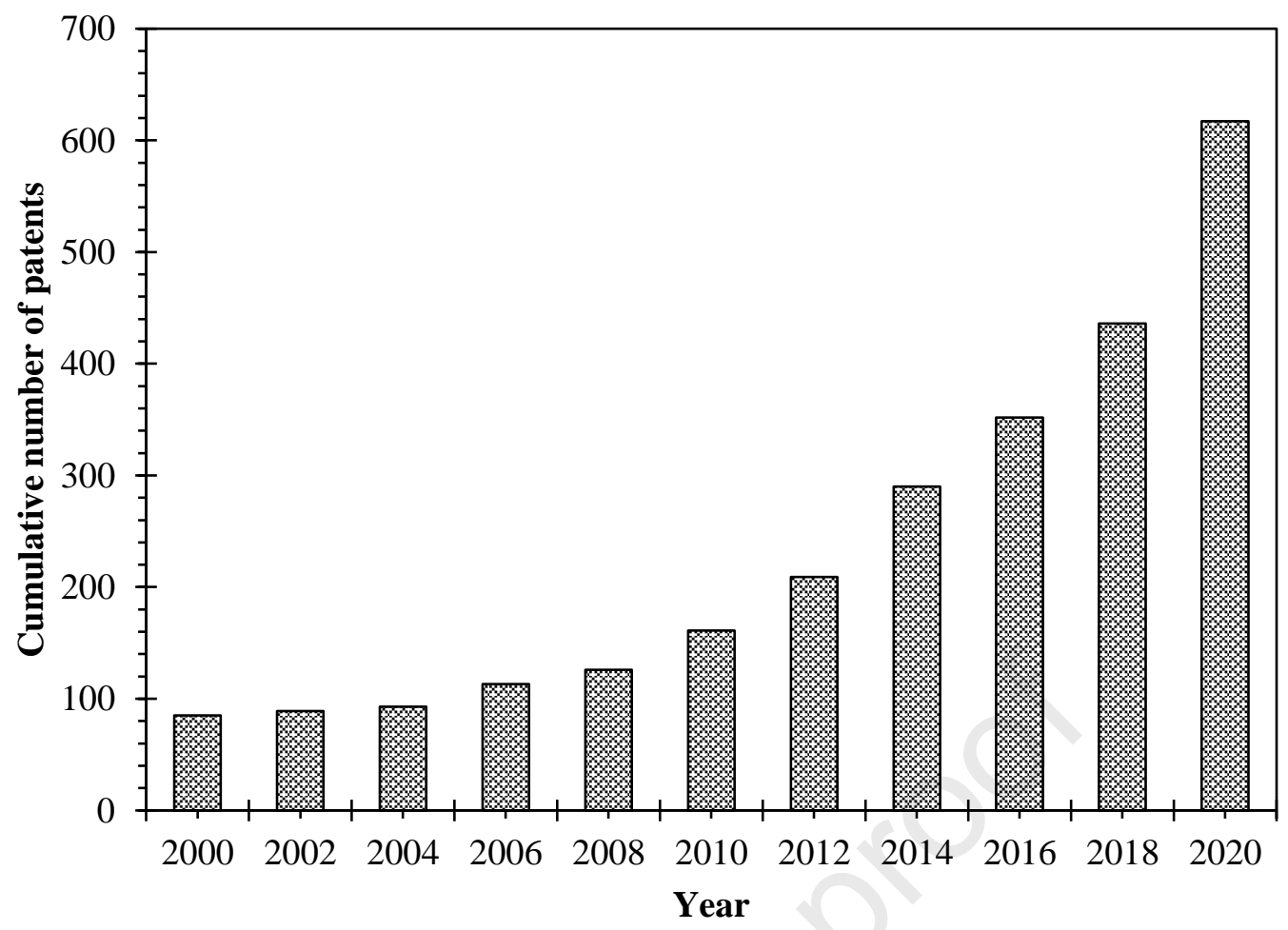

Fig. 4. Number of published patents about IEC devices over the last 20 years [55].

Analysis of the published patents highlighted that the inventions were proposed from different countries (mainly China (62\%) and US (14\%)) and focused on several aspects related to IEC systems, such as HX design (mostly D-IEC), using porous materials, optimization, control, and solar integration, as visualized in Fig. 5. The figure shows that inventors tried to enhance the IEC system by mainly focusing on:

- designing efficient HXs with different structures and materials (254 patents),

- optimizing the HX design with a trade-off between energy efficiency and operating cost (126 patents),

- controlling the operating conditions for IEC to meet the required indoor conditions (151 patents),

- adding porous media in the wet channel to enhance the wettability and correspondingly the heat and mass transfer (67 patents),

- integrating renewable energy, especially solar energy (38 patents),

- efficient use of water in IEC to avoid the aggravation of the world water crisis (14 patents).

As shown in Fig. 5, most patents focused on HX design (254 patents). Fig. 5 also shows that many published patents addressed multiple aspect simultaneously. For instance, 47 patents tried to make innovations in HX design using porous media, 23 patents incorporated renewable energy to power novel HX design, 107 patents disclosed inventions related to HX design and controlling the operating 
conditions, 64 patents tried to control the IEC to optimize the operating conditions and hence reduce the operating and running cost, and 102 patents focused on HX design, cost, and optimization jointly [55]. Analysis of these published patents highlighted the recent interest in D-IEC systems where outlet air temperature is limited by the dew point temperature. This paper reviews recent published patents related to D-IEC technology covering different IEC system designs, such as plate-type, tube-type, and finned-type HX as well as different flow configurations such as parallel, counter, and cross-flow arrangements. Throughout the review of the 458 patents, it is found that there are many international duplicated patents for the same invention filed by the same inventors. So, only the most recent one from such patents is reviewed and discussed. Also, patents that were deemed irrelevant or insignificant are not discussed in the present work. Consequently, the number of patents cited and discussed in the present review is less than 458 patents. The significant patents related to IEC are reviewed, discussed, and presented in a chronological order.

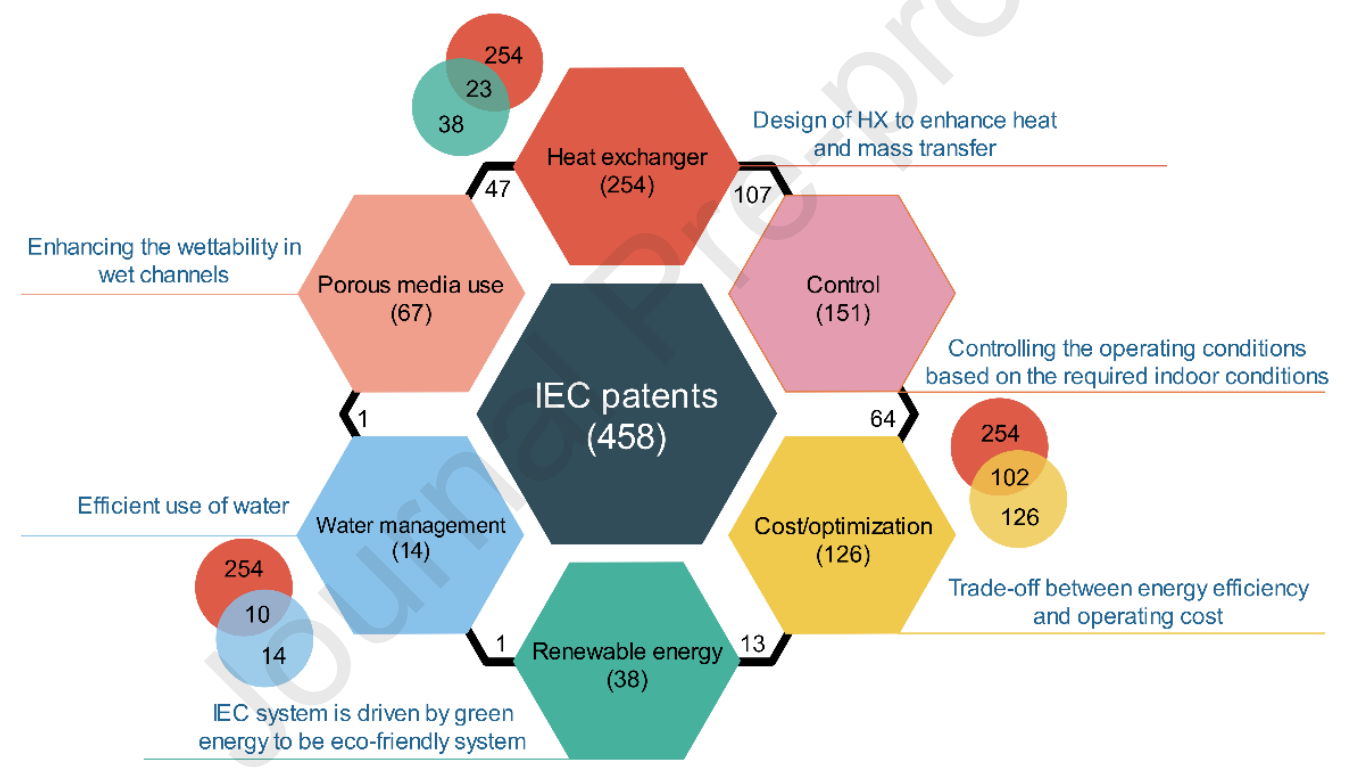

Fig. 5. Topics and aspects related to IEC patents [55]: Numbers inside the hexagons reflect the number of patents involved. The numbers next to the black connected lines reflect the patents that discuss both topics connected hexagons. Other overlaps between patent categories are shown by the colored circles.

\section{Patents review}

Based on the data presented in Fig. 5, this section is devoted to discussing the heat exchanger design, especially the dew-point IEC, using porous media in IEC, powering IEC using renewable energy, and controlling and optimizing IEC.

\subsection{Dew-point indirect evaporator cooler}

The performance of the IEC is greatly impacted by the HX effectiveness [47,56,57]. In 1970, Patent No. US3540702 [58] disclosed a ribbed or zigzag-shaped corrugations heat exchanger. In 
1982, an angularly grooved corrugation HX was proposed in Patent No. US4361426A [59] for a water cooling tower, as drawn in Fig. 6. The grooves have many advantages, such as increasing heat transfer surface area, heat transfer coefficient, and the exposure time to the wetted surface area by directing water flow in a specific downward helical spiral pattern.
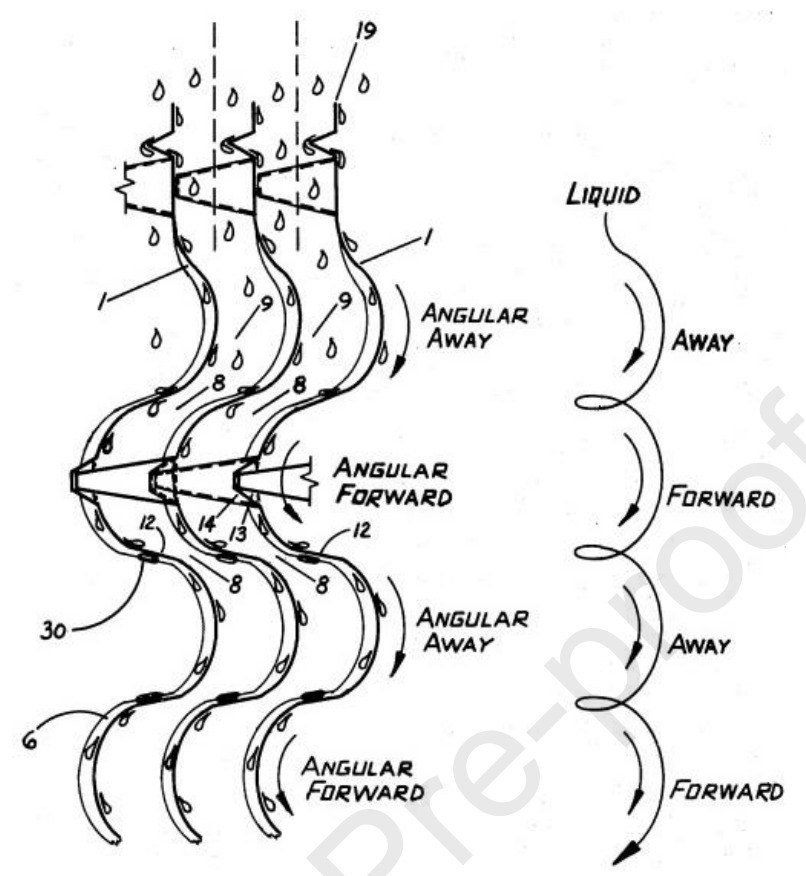

Fig. 6. Grooved channels for heat exchanger [59].

Patent No. US4380910A [60] revealed an evaporative cooling unit with three or more direct and indirect cooling stages for air cooling. In this configuration, the first and second stages were finned coils using saturated media pads. This multi-stage unit was able to cool hot, dry air with only a slight increase in humidity. Patent No. US4977753A [61] disclosed an IEC device wherein a secondary air stream was used and precooled in a countercurrent flow along a moist channel. This invention achieved higher cooling efficiency due to enhanced mass transfer in the moist duct while simultaneously precooling the secondary stream in the dry duct. Patent No. SU1537970A1 [62] showed an IEC device that had housing with a heat exchange nozzle and a pallet located between its outer walls and secondary air streams. The nozzle had radial needles and was designed to have the flexibility of alternating between wet channels. The channels of the HX were slotted and corrugated and separated by moisture-proof heat transfer plates. This arrangement improved the system efficiency. Later, the same group disclosed an invention related to regenerative IEC to achieve higher efficiency and reliability [63] using inclined spring-loaded ribs to reinforce the uniform distribution of the flowing film of water over the surface of channels. Patent No. US4976113A [64] disclosed counter-current IEC HX using wettable capillary-porous material and moisture-proof material for the wet and dry channels, respectively. The cooling efficiency of the device was relatively high due to 
the unlimited reciprocal arrangement of the dry and moist ducts and their variable shapes. This device had relatively low water consumption, leading to a noticeable increase in its performance.

Patent No. US5187946A [65] revealed an IEC design with heat transfer plates inclined at $5^{\circ}$ to $10^{\circ}$ to prevent water droplets from accumulating around the openings and from moving into the dry channels, as shown in Fig. 7. This design also allowed excess water from the wet ducts to drain easily and hence reduce water consumption. Wet channels can be made of polyester, olefin, or nylon. The unit has an aperture that redirects the secondary airflow away from the primary one. Exhausting the secondary air from two sides reduced the pressure drop and energy consumption. This unit was claimed to perform better than the apparatus disclosed in Patent No. US4002040 [66]. Patent No. RU2046257C1 [67] disclosed a D-IEC with plate HX having an inclination angle similar to the device patented in [65]. One side of the plate was made waterproof while the other one was capillary-porous material. Dry and wet channels were formed by alternating the interconnected plates. This arrangement has the advantages of simple construction and easy installation. It was claimed that this device effectively cooled the air and reduced energy costs by 18 to $25 \%$ compared with the known IECs at the time of inception due to the heat exchanger's large surface area.

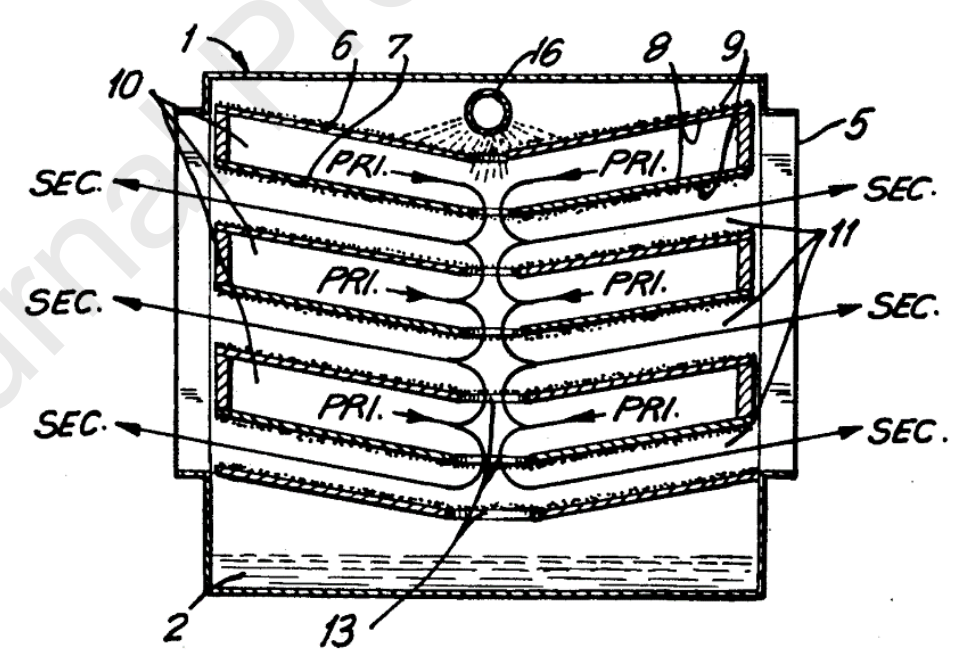

Fig. 7. Plate-type IEC device [65]. Main parts: 5. outlet, 9. porous capillary surface, 10. dry channels, 11. wet channels, 13. apertures, 16. perforated spray header.

Patent No. RU2037745C1 [68] revealed a plate-type IEC in which the walls of dry channels did not have inclination angle and were made using waterproof material. The wet channels were constructed from capillary-porous plates that were made of hydrophobic material with hydrophilic surfaces. The surface hydrophilization ensured capillary transport of moisture to the required height of the capillary-porous plates. It was placed in a pan of water instead of the nozzles used in the patents $[65,67]$. In this patent, ambient air was mixed with room air with a mixing ratio of 1:3 before splitting 
the secondary flow. The mixing ratio was controlled to increase the cooling capacity. The inventors claimed fields of applications in buildings and automotive air conditioning applications. Further improvement in the cooling efficiency was claimed in Patent No. RU2140044C1 [69] using a wet secondary stream with low humidity. Patent No. JP2002206834A [70] revealed an IEC in which the spray area was controlled according to the cooling capacity. Also, its structure has a feature of controlling the location and number of active sprays to control the spray area based on the needed cooling load. This invention aimed to eliminate the problem of impurities disposal in a HX even if the amount of water is limited.

Patent No. US6523604B1 [71] claimed the invention of a plate-type IEC device made from extruded, twin-walled, corrugated, fluted plastic sheeting. Heat transfer was enhanced in the primary channels using high surface area aluminum mesh. Secondary channels' heat and mass transfer were improved using an evaporative mech or pad with a high surface area. Patent No. WO2005090870A1 [72] showed a different design of IEC in which each plate has a wet side and a dry side, and the dry sides of adjacent plates face each other, as shown in Fig. 8. The plate had perforations between the dry and wet sides, providing flow from the dry channels to the wet channels in which direct evaporative cooling occurs. The wet side was designed in such a way that the working air moved in a direction counter to the inlet air. This was different from the HX presented in the invention of Patent No. US6581402B2 [73], which had a cross-flow configuration in wet and dry channels, allowing heat transfer through the plates. In 2010, the same inventors added edges to the plate of the HX to remove excess liquid and minerals away from the heat transfer section, and hence enhancing the IEC effectiveness [74]. Patent No. CN100359249C [75] disclosed an IEC unit that reused wet energy, reducing power consumption and operating cost. This unit can be configured as single or multi-stage IEC cooling either gas or liquid in the primary channels. When air is the primary fluid, its temperature can be lower than its original wet bulb temperature and near its dew-point temperature at constant moisture content. Accordingly, the IEC web-bulb efficiency could reach $100 \%$. 

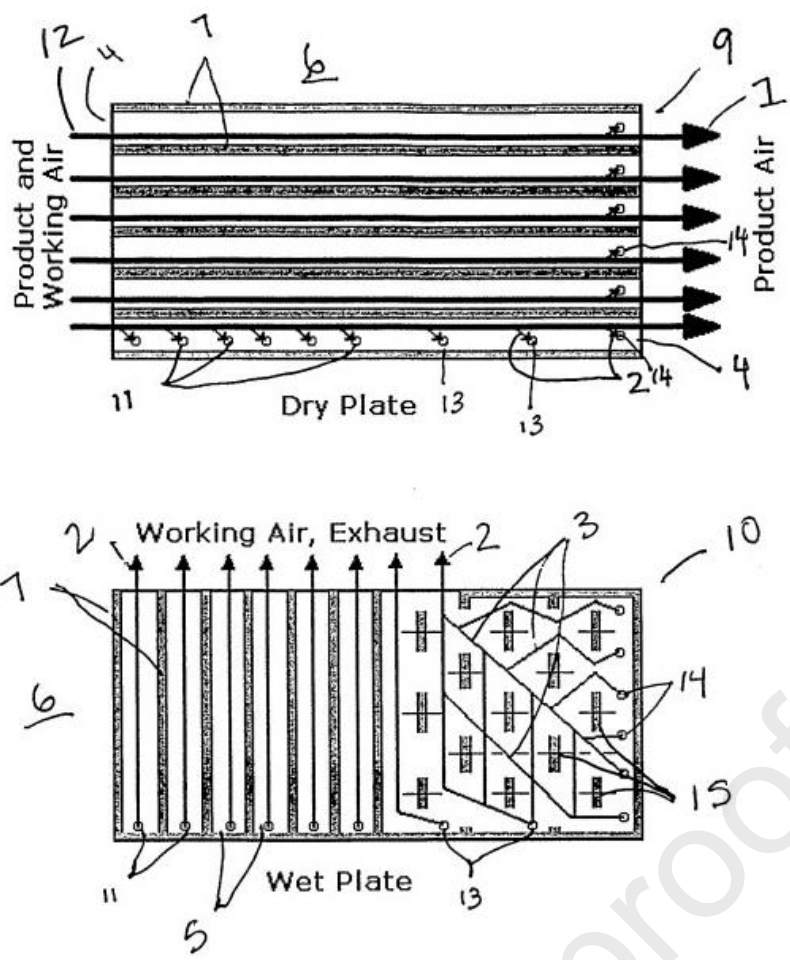

Fig. 8. Plan view of the dry side (top) and plan view of the dry side (bottom) of IEC [72]. Main parts: 3. wet side paths, 4. dry channels, 5. wet channels, 7. channel guides, 11. input end side perforations, 13. output end side perforations, 15. wet side path barriers.

Patent No. KR20090019326A [76] disclosed an improved HX design that solves the airflow non-uniformity issues in typical IEC systems that arise from the contact between air and water, thereby minimizing the degradation in cooling performance because of the flow irregularity. This invention depended on equalizing the flow rate of bleed air flowing into the guide duct (170), as shown in Fig. 9. This can be seen from the change in the flow rate of bleed air according to the distance between the base and the exhausts. The figure shows that the dry and wet channels were alternately arranged on the base to form the HX. The secondary air passing through the wet channel was discharged to the outside through the guide duct. Patent No. CN201377870Y [77] revealed a heat pipe-type IEC in which the condensation part of the heat pipe was coated with a water absorbent and a spray device was used on the outside the condensation part. This unit produced air at a temperature near its dew point and consumed lower energy than traditional IEC systems by 10 to $20 \%$. Patent No. CN101266091A [78] disclosed a dew point plate-fin IEC that employed porous functional ceramics. The main feature of this invention was the uniformity of water distribution, which improved the heat and moisture exchange efficiency. A similar invention using square porous ceramics vertical-tube dew point IEC was disclosed in Patent No. CN101329104A [79]. Equal water distribution allowed the temperature of process air to approach the dew point. Patent No. CN101761997A [80] revealed a countercurrent D-IEC device using a nozzle atomizer to provide small and clean water droplets to the wet channel. This device was proposed for use in humid areas in China with a COP of about 9.4. A 
multi-channel plate-fin type D-IEC unit was revealed in Patent No. CN102095320A [81]. Substituting the IEC of two (dry and wet) channels with the D-IEC employing fins improved heat exchange efficiency and reduced energy consumption. Patent No. CN102494398A [82] disclosed a reverse-flow, indirect-direct two-stage D-IEC having double flash evaporation cooling to cool the process air to nearly the dew point of the outdoor air. It was found that the reverse-flow structure enhances the efficiency of the evaporative cooler.

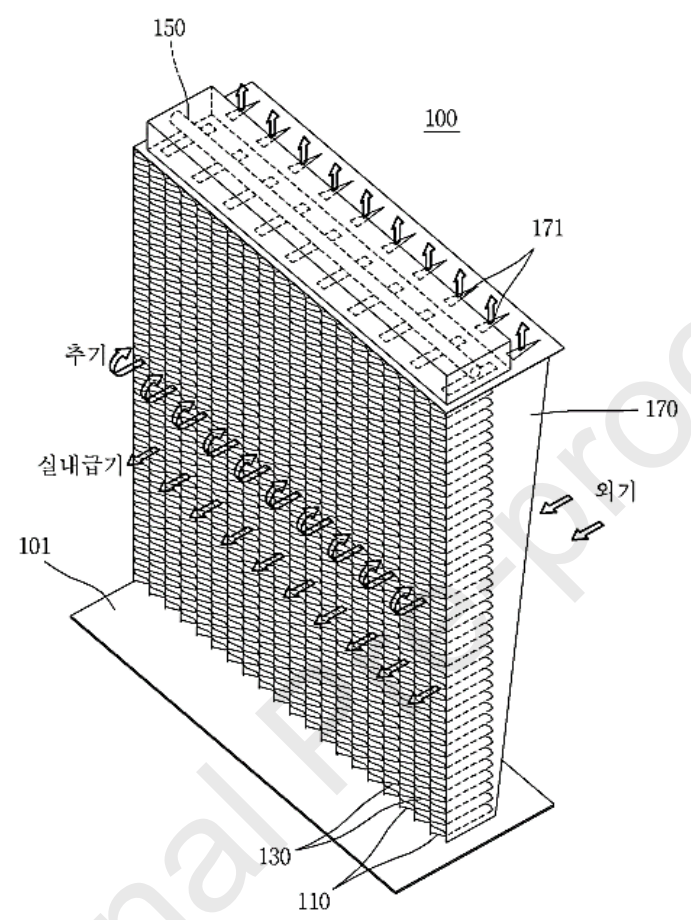

Fig. 9. R-IEC [76]: 101. base, 110. dry channel, 130. wet channel, 150. water spray unit, 170. guide duct, 171. exhaust ports.

Patent No. US20140183764A1 [83] revealed an IEC HX in which a plenum was adapted to use part of the primary air as secondary air. Patent No. CN104534603A [84] claimed the replacement of baffles with internal dividing structure in a countercurrent plate type D-IEC system. Inventors claimed that this would reduce the pressure drop and hence the fan power, resulting in a reduced system's energy consumption. A 0.1 to $0.4 \mathrm{~mm}$ clapboard was added between each dry and wet channel. The surface of clapboard facing the dry channel was hydrophobic, while the surface facing the wet channel was hydrophilic. Secondary flow can enter wet channels through holes formed in the clapboard. The hydrophobic and hydrophilic surfaces were adapted using electrostatic flocking process (i.e., using electric charge to arrange fibers in perpendicular alignment). The cooling performance was enhanced due to the thinner wall thickness employed. Conventional D-IEC system having many walls result in high pressure drop, and hence negative pressure zones may be experienced. Patent No. CN103994677A [85] revealed the use of corrugated sheets and sealing 
bodied to construct dry and wet channels of the IEC device. This approach aimed to strengthen the structure of the IEC system without adding extra support and increasing the draught area of a passage, therefore reducing the pressure drop. Patent No. WO2016022039A1 [86] showed an IEC system from stack of plates made with plates that had capillary-porous material with protrusions on one side, while the other side has a waterproof coating. About $90 \%$ of the heat transfer area of the plate was only coated, leading to an enhancement in cooling effectiveness.

Patent No. CN105783340A [87] revealed an intersected cross-flow IEC system comprising three regular six-face IEC units; each has a hexagonal cross-section. This construction was reported to deliver cool air with a temperature approaching the dew point that increased the efficiency, which was limited to 80\%. A triple channel IEC unit was disclosed in Patent No. CN206531212U [88]. The invention comprised mutually isolated and staggered three channels: a primary air, dry secondary air, and wet secondary air channel. In this configuration, the secondary air stream moved first through the dry secondary air channel and then the wet channel. Primary air went through the dry channel to exchange heat with equal reverse flow of secondary dry air, achieving cooling for primary air. The air flow in this invention was countercurrent flow. Patent No. CN106595355A [89] disclosed a Zand L-shaped channels and used them as dry channels while the wet channels were straight. Air was precooled by moving through L-shaped channels then through the wet channels. The primary air was crossflowing in a Z-shaped channel to be cooled by exchanging heat with another stream, realizing a high wet-bulb effectiveness reaching $120 \%$. This was because the Z-shaped channels have higher heat transfer surface area and lower air flow resistance than the L-shaped channels. Patent No. CN108362043A [90] disclosed a tubular (pipe) type D-IEC device in which hygroscopicity (i.e., attracting water without bonding) hydrophilic material was coated on the HX tubes. The tubes had equally distributed holes to form a stable and uniform moisture film to enhance heat transfer efficiency. This arrangement allowed the wet bulb effectiveness to reach $100 \%$. Patent No. CN209783354U [91] revealed a new plate type IEC HX design. The primary air channel was made of a transparent plastic shell, while the outer sides are wrapped by rubber to reduce heat loss. This design solved the problem of condensation that may occur on the plate surface of the primary air channel, which reduces the heat exchange efficiency. Patent No. CN110469929A [92] revealed the design of the IEC unit shown in Fig. 10. The design consisted of mutually isolated dry passage and wet channels. The crossflow arrangement was reported to produce cold air at nearly the dew point temperature of outdoor air with a simple structure. Patent No. CN108826539A [93] disclosed a vertical structure, compact-sized, finned D-IEC system to solve technical problems related to conventional D-IEC devices such as size and material utilization. In this invention, recirculated water was directly sprayed on porous material under the gravity effect to reduce water and electricity consumption. Such arrangement enhanced the heat exchange effectiveness and the cooling efficiency 
ratio. Patent No. CN210891996U [94] disclosed an IEC device in which the vertical and horizontal channels were wavy. Air passes through the dry channel to precool. Then, a part of this stream passes through the wet channels through holes to exchange heat with the air that moves inside the dry channels. This approach was found to be flexible in controlling the humidity of primary air. Patent No. CN212108847U [95] revealed the utilization of a movable water distributor in a cross-flow DIEC to make the water distribution homogeneous. This invention helped in solving problems related to scale deposition and relatively high energy consumption. Patent No. CN212457244U [96] claimed the use of a corrugated partition to divide the core of IEC HX into dry and wet parallel channels. This arrangement interrupted the thermal boundary layer and increased the heat transfer surface area, leading to an improvement in heat transfer and unit efficiency, but increased the flow resistance.

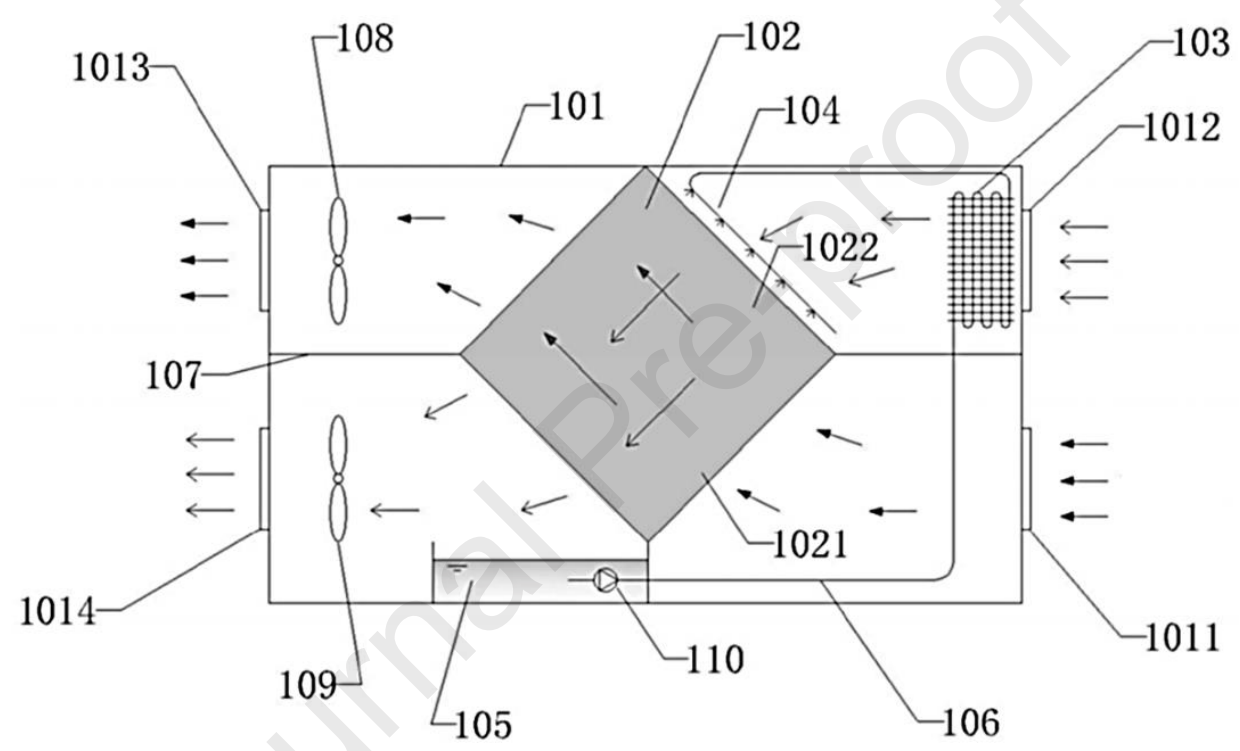

Fig. 10. Schematic of D-IEC unit [92]. Main parts: 102. IEC core, 103. surface air cooler, 104. spray, 107. partition, 1011. primary side air inlet, 1012. secondary side air inlet, 1021. dry channels, 1022. wet channels.

\subsection{Porous material-assisted IEC and water management}

The heat and mass transfer in the wet channels are the key factors affecting the performance of IEC systems. Also, recycling the water and capturing the water droplets to prevent water from escaping the system should be considered in designing the IEC systems to save water use and increase the device efficiency. Porous materials with high wettability have been employed in IEC units to achieve good wettability and reduce the water consumption.

In 1977, Patent No. SU571668A1 [97] showed an IEC unit constructed from moisture-proof and capillary-porous layer as dry and wet channels, respectively. This invention proved that the good wettability of the capillary-porous layer enhances the device efficiency remarkably. Patent No. 
WO2001057460A1[98] revealed an IEC HX in which the wet channels were made of laminate material having a sheet of wicking material, while the dry channels were made of a waterproof plastic material. The plastic section was molded with ridges to provide stability and rigidity to the plastic. A portion of the wet plates can be made of membrane material, covered by a solid desiccant material from the opposite side. This configuration provided evaporative cooling and dehumidification simultaneously. The novel structure of the invention increased the efficiency, economy, and productivity of the IEC unit. The main drawback of this HX was the poor heat transfer that occurs with plastic of this thickness [99]. Patent No. WO2005119156A2 [100] revealed the utilization of a membrane to separate the supply air and secondary air. This design had the flexibility of transverse wall movement of about $0.635 \mathrm{~mm}$ (0.025 inches) when the pressure increases. The temperature drop across the membrane was small (less than a degree Fahrenheit). In contrast, the temperature difference between the two bulk air streams was 5.5 to $22^{\circ} \mathrm{C}$. Patent No. CN201187850Y [101] claimed the use of a hydrokinetic type spray chamber in tube-type IEC. The spray was not easily blocked and had low resistance with high efficiency. The inventors claimed that the system was economical and environmentally friendly with low cooling cost.

Patent No. WO2010054426A1 [102] showed a design of an IEC in which the wet and dry channels were constructed from corrugated sheets with one side being a wettable and absorbent medium. At the same time, the other side was a membrane surface. This approach provided a uniform wetting, leading to cooling efficiency enhancement. Patent No. CN102168929A [103] revealed adding a substrate between dry and wet channels. The substrate was made of porous plastic material with low thermal conductivity. This configuration reduced the weight of the unit and improved the cooling effect by about 30\% compared with previous units. Patent No. CN102116512A [104] claimed a plate-type IEC in which uniform moisture film was formed using hydrophilic surface treatment or wettable materials. A water spray pipe with two rows of holes was disclosed in this invention. Problems related to scaling, blocking, and biohazard were solved in this design, leading to low energy consumption. Patent No. CN201731786U [105] disclosed a heat pipe IEC in which absorbent material was wrapped on the hot ends of heat pipe. In this invention, A three-dimensional spray circulating water pipe was used to distribute the water. This approach allowed even water distribution, good heat dissipation, and improvement in cooling efficiency. Patent No. CN101818997A [106] revealed parallel flow, finned tube IEC wherein water retaining material was employed in the wet channels. A spray water pipe was used to spray water downwards, which is simple, but the design suffered from blocking and fouling of channels because they were narrow. However, the system was claimed to be efficient due to the enhancement in heat and mass transfer. Patent No. CN203216313U [107] disclosed the use of expansion moisture film plate in tube-type IEC. A spray arm was connected to recirculating pump water to form a liquid film that flows from top to bottom. This approach increased 
the heat and mass transfer and hence improved the cooling effectiveness. Patent No. US20140262163A1 [108] revealed the use of a membrane to separate between dry and wet channels. Short and stubby fins were formed on the inner wall surfaces to enhance the heat transfer. This design produced chilled water as well as cold air at high efficiency. Patent No. US9140471B2 [109] disclosed a practical evaporative cooling plate having both direct and indirect evaporative sections as depicted in Fig. 11. This unit was constructed by alternating the liquid passing through the passage defined by a membrane and separate wall to provide a plurality of liquid and air flow channels. The liquid desiccant used in this unit could be any hygroscopic liquid that can absorb moisture from the air stream. Typical liquid desiccant used can be easily regenerated including glycol and ionic salt solutions. Vortex generators, pattern of features, or fins were used for heat transfer enhancements. This unit could simultaneously dehumidify and cool the inlet air stream. Patent No. CN206771588U [110] revealed the design of a countercurrent IEC using polymer-porous ceramics composite membrane. The polymeric material was evaluated and found to be tough enough for this application. It was also found to have good waterproof performance and capillarity. These features made the IEC device more efficient. Patent No. US20190107332A1[111] disclosed an IEC with a water collection and management system installed below the HX to collect water sprayed onto it. The spray system was designed to maintain even wetting for the surfaces of the wet channels and hence improving the cooling efficiency.

Patent No. WO2020072597A1 [112] revealed an IEC system using porous ceramic material similar in design to the M-cycle. It was formed by additive manufacturing. In their design, the dry channels had a barrier layer to prevent water vapor from entering. The barrier layer was roughened with less than $1 \mathrm{~mm}$ features and treated chemically to be hydrophobic. This texture enhanced the cooling effect, allowing the primary air temperature to approach dew-point temperature without changing its humidity ratio. Patent No. US20200284452A1 [113] claimed a multi-stage IEC system consisting of two stages of IEC with two separate IEC HXs. The dehumidification system was one of an adsorption dehumidifier and separation membrane dehumidifier. An air blower was used to suck air through the first stage and then push air over to the second stage. This invention achieved a webbulb effectiveness greater than 82\%. Patent No. US10739079B2 [114] showed an IEC that was constructed from a porous, wicking, hydrophilic material and fins or other protrusions were added to the air passages to augment heat transfer. In this design, hot outdoor air enters the channels through a wetted, porous pad to be cooled and humidified, then used to cool the primary air. The proposed design achieved less air-side pressure drop, lower water consumption, and higher cooling efficiency, compared with previous designs. Patent No. EP2250446A1 [115] revealed an IEC unit wherein the dry and wet flow channels were separated by membranes. Water vapor transfers through the 
membrane absorbed by the liquid desiccant that was cooled by coolant. Solar heat was proposed as a heat source for desiccant regeneration to facilitate the continuous operation of the IEC system.

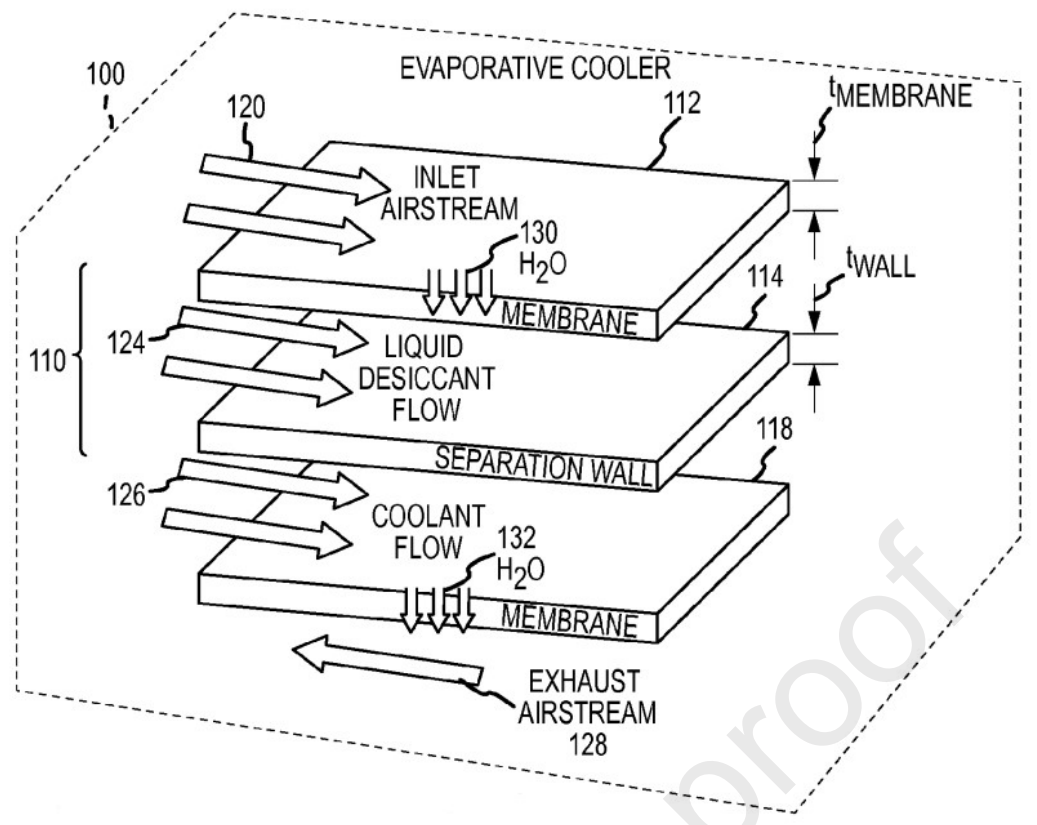

Fig. 11. Innovative evaporative cooler [109].

\subsection{Renewable energy powered IEC}

Renewable energies, such as solar energy, were proposed as a source for driving the fans and pumps used in IEC systems to reduce the operating cost and make the technology eco-friendly. Photovoltaic (PV) systems are the dominant technology integrated with the IEC systems. Patent No. US4827733A [116] disclosed an EC unit that had two heat pipe devices and two HXs (i.e., evaporator and condenser), as shown in Fig. 12. It was claimed that this invention produces cooling power at a low cost as it was powered by a PV system to drive the fans and pumps. Patent No. US20120047937A1 [117] revealed an IEC integrated with solar panels to provide power during the daytime and charge the batteries for night-time use. The system was light and mobile. Dry channels were made of porous, light weight, and UV-rated high strength polypropylene plastic plates. The wet channels were filled with highly breathable fabric sheets or fibers. This design had a feature of thin and strong walls and could cool down outside air from $43^{\circ} \mathrm{C}$ to 18 to $21^{\circ} \mathrm{C}$. Also, the design was suitable for cooling gases or fluids other than ambient air. 


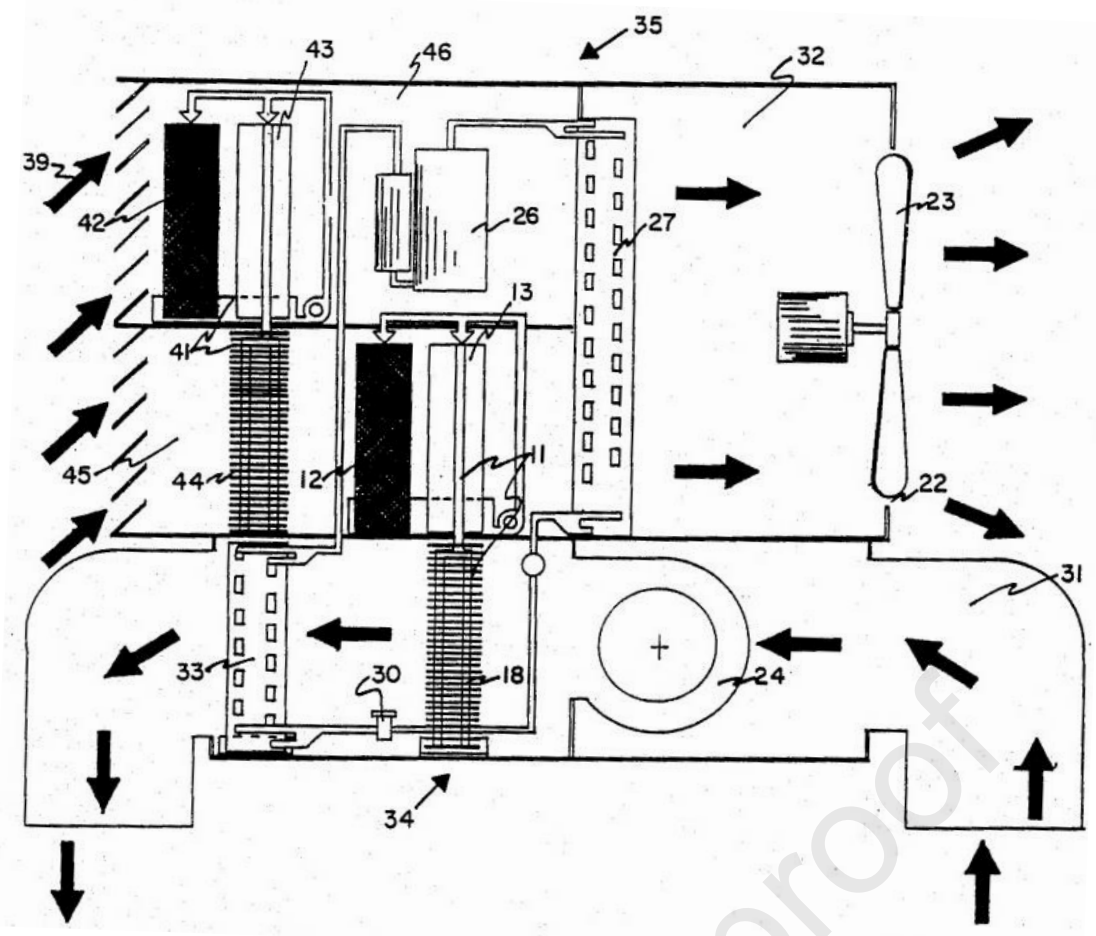

Fig. 12. Schematic of a two-stage IEC unit [116]. Main parts: 11. heat pipe, 12 and 42. wet pads, 23 and 24. fans, 26. compressor, 27. condenser, 31. inside air duct, 33. evaporator, 39. hot, dry air stream, 45. hot, humid air stream.

Patent No. CN204786979U [118] claimed the use of solar PVs to power the fan and the water pump of the IEC device to reduce its operating cost. The inventors claimed the use of a wavy tube heat exchanger, which increased heat transfer surface area and improved the heat exchange efficiency. Patent No. CN106765755A [119] disclosed a PV powered D-IEC system to avoid problems arising from the high energy consumption of data centers. The proposed system can guarantee the normal operation of the AC system and significant reduction in electricity consumption. A similar system was also proposed in Patent No. CN110753479A [120] to avoid local hot spots in cabinets, save energy and reduce emissions. This invention claimed the use of open air cycle contrary to the use of a close air cycle disclosed in [118].

\subsection{Control and optimization}

The efficiency of the IEC systems depends on the operating conditions. Precision control over the operating conditions and parameters results in improved D-IEC efficiency. Patent No. CN104121648A [121] revealed a temperature and humidity independent control system using an IEC unit that has a HX, water supply, and water distribution device. By using a warm and humid independent control approach, this system can simultaneously obtain a small amount of cold air and cold water. Patent No. KR101878367B1 [122] employed temperature sensors to control the operation of the water supply pump, which was turned off when the outside air temperature was lower than a 
preset temperature. This allowed for improved cooling efficiency and reduced the energy consumption. Patent No. CN107830596A [123] claimed the installation of a temperature and humidity sensors at the inlet and exit of the wet channel and temperature sensors at the inlet and exit at the dry channel. Based on these measurements, the airflow rates of both channels were controlled to achieve higher cooling capacity under variable working and environmental conditions. Patent No. CN210569050U [124] disclosed a control system for IEC systems used in data centers. The control system comprised sensors, a controller, and a management server. The temperature and humidity were measured inside and outside the data center. The operating parameters of the IEC unit were controlled by a controller which collects data from the sensors. A control command was generated by a management server, allowing the control of the installed IECs. The suggested control system allowed to optimize the control scheme strategy based on the internal load. Also, any fault that occurred can be solved instantaneously to ensure safe operation of the machine room. Patent No. CN111295084A [125] disclosed an IEC system in which primary and secondary airflow rates were controlled using motorized air dampers. These dampers open and close according to the outdoor conditions. Also, the water pump was controlled to adjust the water flow rate according to the airflow rate. This control aimed to save energy and improve the efficiency and cooling capacity.

Patent No. CN111750464A [126] claimed the use of temperature, humidity and differential pressure sensors to control the operation of IEC systems for data centers. The differential pressure and temperature sensors were installed in the dry and wet channel, respectively. Their signals were wired to a controller for controlling the primary fan speed. This control system aimed to stabilize the return air temperature, indicating a stable cooling load and reduced energy consumption. Patent No. US10820452B2 [127] revealed a control system to satisfy the dynamic thermal requirements of data centers and information technology (IT) rooms using IEC devices. Temperature and pressure sensors installed in the data center and IT rooms were utilized to measure thermal performance. A controller was used to change the operating conditions such as fans speed and mist volume. The main goal of the control system was to specify optimal operating conditions based on the load of the machine room and hence achieve high efficiency and low energy consumption. Patent No. CN109827269A [128] revealed an invention relating to the fan control method of IEC systems in which the fan speed was adjusted based on the outdoor temperature. The indoor fan was also under control based on the outdoor fan to set the value of the supply air temperature accordingly. Such control scheme showed a direct positive effect on the energy consumption of the entire unit. Patent No. CN111594962A [129] disclosed fluorine circulating pump energy-saving IEC device and a control method. The water supply pump and circulating fans were connected to a controller to adjust their speeds and hence the flow rates to meet the thermal requirements. Besides, the outdoor airflow was controlled to adjust the temperature change across the HX. This control system was found to achieve low energy 
consumption. Patent No. WO2020151112A1 [130] disclosed a spray control method for cold-source water pump for IEC systems. The water pump was turned on and off based on the outdoor temperature. It was turned on when the water temperature was lower than the outdoor temperature, saving water and enhancing heat transfer inside the HX. Patent No. CN211503094U [131] revealed an IEC bypass system connected with a control mechanism. The control unit was connected with an outdoor air temperature sensor, exhaust valve, and bypass valve. The bypass and exhaust valves were controlled based on the outdoor air temperature. The inventors claimed that this control unit could effectively control the air supply temperature and achieve higher cooling efficiency. Patent No. CN112268326A [132] revealed an invention of IEC with a control method to maximize the energy utilization rate. The flow rate of the circulating cooling water entering the wet channels was controlled. Also, air dampers were controlled to adjust the flow rate based on real-time temperature measurements. This approach allowed suitable control of the operation of the system. Patent No. CN112228982A [133] disclosed an intelligent control method for IEC systems. This controller had modules for temperature detection, humidity detection, and cooling analysis. The cooling analysis module relied on temperature and humidity sensors of indoor and outdoor conditions, and air in the flow channels. Based on the results of the cooling analysis module, the operation of the IEC module was adjusted to control the supply temperature. This suggested control method achieved better cooling and energy saving than prior methods.

\section{Current research gaps and outlook}

The literature and patent review presented earlier highlights that several technology gaps need to be covered in the near future to increase the efficiency of the IEC technology for space cooling applications. Although different flow arrangements between the primary and secondary air streams have been extensively proposed, there is still room for improving the system efficiency by optimizing the flow configurations and geometric parameters. Multi-stage IEC is a promising technology, but it still needs further investigations to assess its applicability in different climates. In hot and humid conditions, outdoor air might condense in the dry channels, more likely when the surface is hydrophilic. This condensation, mostly filmwise, causes additional thermal resistance to the HX which negatively affects the system efficiency. Water distribution and spraying are extensively disclosed in patents, but sprayers' characteristics, such as mass flow rate, spray cone angle, and water temperature, have not been fully developed. Patents have also revealed the use of porous media to enhance surface wettability; however, this technology does not necessarily guarantee the entire surface is wetted. Furthermore, cleaning porous media remains a challenge, and different approaches should be proposed. Thus, using a more suitable wicking approach to provide uniform surface wettability is still a research gap that needs more work. Hydrophobic and hydrophilic surfaces have 
been widely disclosed, but their durability, stability, and sustainability are yet to be verified. The current review paper also revealed a lack in the invented water spraying systems that could improve the system performance. In addition, environmental impacts relating to the IEC system received less consideration in previous patents. The cost of the current state-of-the-art of IEC technology is still not well studied and not representative of adoption at scale. Therefore, more work should focus on cost analysis. Renewable energy integration promises significant operating cost reduction and environmental advantages over baseline technologies. However, the public literature is lacking detailed techno-economic assessment of the integration between the IEC system and solar energy needs. Furthermore, technology commercialization studies are scarce for this promising technology. This is partly due to the limited potential to scale this technology. It is currently suited for mediumscale commercial applications. However, the large geometrical size of IEC devices is a barrier facing commercialization. With the current growth in the room air conditioning market, there is a pressing need to scale it down to $3 \mathrm{~kW}$ of cooling or less. Furthermore, inventions related to mass production and ease of installation should be sought to improve market penetration. In general, the research and development community is still looking for an efficient, compact, and mobile IEC system at low operating cost and low energy consumption.

According to the above technology gaps and challenges, future research and development work related to the IEC systems should focus on (1) HX design and material; (2) surface wettability; (3) water distribution and management; (4) techno-economic feasibility; (5) environment (i.e., carbon footprint assessment) and social impacts; and (6) production and commercialization. Making innovations in these aspects related to IEC technology will eventually contribute to realizing an improved market share growth of IEC products. The share of IEC technology in the air conditioning market is expected to increase remarkably in the next decades, especially in dry and hot climatic regions, such as the Middle East, Africa, and East Asia.

\section{Conclusion}

Engineers and inventors are striving to design efficient IEC devices that could handle the sensible load of buildings regardless of the ambient conditions. The present paper comprehensively reviews the patents published in the last four decades about IEC technology. It can be concluded that most of the inventions focused on efficient design and optimization of the D-IEC system to improve its efficiency. The M-cycle has better performance than the conventional IEC system, but requires complex construction to accommodate the required flow pattern. Roughened layers and baffles are used in IEC systems to promote the heat transfer. This came at the cost of higher pressure drop and energy consumption. Fins and protrusions are also used to enhance the heat transfer in dry channels. Regarding the flow arrangement, the counter-flow configuration provides better cooling efficiency 
and system compactness compared with crossflow configuration due to efficient energy recovery. The inventors recognized that the convective air heat transfer coefficient on the dry side of IEC (e.g., dry side of the separator plates) is generally the limiting factor in how small an IEC device can be constructed. As a result, enhancing the convective heat and mass transfer coefficients is of primary importance to enable compact IEC system designs.

Efficient HX is a key parameter that affects the performance of IEC. The HX is usually made of single-side waterproofed cellulose fiber, aluminum tube/plate with grooved or meshed side, or ceramic tube/plate. The size of the heat transfer sheet is controlled by the natural limit of the capillary effect to dampen the wet passages. Additionally, heat and mass transfer in the wet channel is one of the key factors affecting the performance of the IEC system. Porous materials with high wettability, which could be porous ceramic or fiber (membrane), have been employed in IEC units. Such materials should be selected based on their strength, durability, contamination risk, compatibility with waterproof coatings, and cost. Fiber is not an option because fibers are easily deformed or damaged after being wetted by water. A composite membrane with a hydrophobic surface is proposed to be on the side of the dry channel of the IEC HX.

Renewable energy, such as solar energy, integrated IEC systems reduce the operational costs and carbon emissions. Controlling the operating conditions and optimizing the design parameters were found to be critical to achieve improved performance. The present work identified the current technology gaps and future research and development related to IEC devices in the areas of HX design and material selection, surface wettability, water distribution and management, techno-economic feasibility, environment and social impacts assessment, and production and commercialization.

\section{Acknowledgment}

This work is part of project No. 3988 funded by the office of sponsored research at King Abdullah University of Science and Technology (KAUST). The authors would like to acknowledge the support from Dr. Rory Jordan at KAUST.

\section{Declaration of Competing Interest}

The authors state that they have no known competing financial interests or personal relationships that could have influenced the work reported in this paper. 


\section{References}

[1] M.W. Shahzad, M. Burhan, L. Ang, K.C. Ng, Energy-water-environment nexus underpinning future desalination sustainability, Desalination. $413 \quad$ (2017) 52-64. https://doi.org/10.1016/j.desal.2017.03.009.

[2] Electricity Information 2019 - Analysis - IEA, (n.d.). https://www.iea.org/reports/electricityinformation-overview (accessed January 20, 2022).

[3] The Future of Cooling, Futur. Cool. (2018). https://doi.org/10.1787/9789264301993-en.

[4] H. Esen, M. Inalli, M. Esen, A techno-economic comparison of ground-coupled and aircoupled heat pump system for space cooling, Build. Environ. 42 (2007) 1955-1965. https://doi.org/10.1016/j.buildenv.2006.04.007.

[5] Launch of the 2020 Global Status Report for Buildings and Construction | World Green Building Council, (n.d.). https://www.worldgbc.org/news-media/launch-2020-global-statusreport-buildings-and-construction (accessed January 3, 2022).

[6] Aakash C.Rai, Energy performance of phase change materials integrated into brick masonry walls for cooling load management in residential buildings, Build. Environ. 199 (2021) 107930.

[7] F. Lu, Z. Yu, Y. Zou, X. Yang, Cooling system energy flexibility of a nearly zero-energy office building using building thermal mass: Potential evaluation and parametric analysis, Energy Build. 236 (2021). https://doi.org/10.1016/j.enbuild.2021.110763.

[8] J. Chen, L. Lu, Development of radiative cooling and its integration with buildings: A comprehensive review, Sol. Energy. $212 \quad$ (2020) 125-151. https://doi.org/10.1016/j.solener.2020.10.013.

[9] R. Zeinelabdein, S. Omer, E. Mohamed, Parametric study of a sustainable cooling system integrating phase change material energy storage for buildings, J. Energy Storage. 32 (2020). https://doi.org/10.1016/j.est.2020.101972.

[10] O. Eneja, U. Stritih, Review on compression heat pump systems with thermal energy storage for heating and cooling of buildings, J. Energy Storage. 39 (n.d.).

[11] S. Seyam, Types of HVAC Systems, 2018. https://doi.org/10.5772/intechopen.78942.

[12] O. Amer, R. Boukhanouf, H.G. Ibrahim, A Review of Evaporative Cooling Technologies, Int. J. Environ. Sci. Dev. 6 (2015) 111-117. https://doi.org/10.7763/IJESD.2015.V6.571.

[13] H. Yang, W. Shi, Y. Chen, Y. Min, Research development of indirect evaporative cooling 
technology: An updated review, Renew. Sustain. Energy Rev. 145 (2021). https://doi.org/10.1016/j.rser.2021.111082.

[14] What are the benefits of evaporative cooling for the manufacturing sector?, (n.d.). https://www.cosaf.co.uk/blog/what-are-the-benefits-of-evaporative-cooling-for-themanufacturing-sector (accessed January 20, 2022).

[15] W. Li, W. Shi, J. Wang, Y. Li, J. Lu, Experimental study of a novel household exhaust air heat pump enhanced by indirect evaporative cooling, Energy Build. 236 (2021) 110808. https://doi.org/10.1016/j.enbuild.2021.110808.

[16] Y. Al Horr, B. Tashtoush, N. Chilengwe, M. Musthafa, Operational mode optimization of indirect evaporative cooling in hot climates, Case Stud. Therm. Eng. 18 (2020). https://doi.org/10.1016/j.csite.2019.100574.

[17] Q. Chen, M. Burhan, M.W. Shahzad, D. Ybyraiymkul, F.H. Akhtar, K.C. Ng, Simultaneous production of cooling and freshwater by an integrated indirect evaporative cooling and humidification-dehumidification desalination cycle, Energy Convers. Manag. 221 (2020). https://doi.org/10.1016/j.enconman.2020.113169.

[18] D. Pandelidis, A. Cichoń, A. Pacak, P. Drąg, M. Drąg, W. Worek, S. Cetin, Water desalination through the dewpoint evaporative system, Energy Convers. Manag. 229 (2021). https://doi.org/10.1016/j.enconman.2020.113757.

[19] A. Çayl1, A. Akyüz, S. Üstün, B. Yeter, Efficiency of two different types of evaporative cooling systems in broiler houses in Eastern Mediterranean climate conditions, Therm. Sci. Eng. Prog. 22 (2021). https://doi.org/10.1016/j.tsep.2021.100844.

[20] H.M.U. Raza, M. Sultan, M. Bahrami, A.A. Khan, Experimental investigation of evaporative cooling systems for agricultural storage and livestock air-conditioning in Pakistan, Build. Simul. 14 (2021) 617-631. https://doi.org/10.1007/s12273-020-0678-2.

[21] Evaporative Coolers | Department of Energy, (n.d.). http://energy.gov/energysaver/evaporative-coolers (accessed August 29, 2021).

[22] J. Lin, R.Z. Wang, M. Kumja, T.D. Bui, K.J. Chua, Multivariate scaling and dimensional analysis of the counter-flow dew point evaporative cooler, Energy Convers. Manag. 150 (2017) 172-187. https://doi.org/10.1016/j.enconman.2017.08.003.

[23] M. Ali, W. Ahmad, N.A. Sheikh, H. Ali, R. Kousar, T. ur Rashid, Performance enhancement of a cross flow dew point indirect evaporative cooler with circular finned channel geometry, J. Build. Eng. 35 (2021). https://doi.org/10.1016/j.jobe.2020.101980. 
[24] S. De Antonellis, C.M. Joppolo, P. Liberati, S. Milani, L. Molinaroli, Experimental analysis of a cross flow indirect evaporative cooling system, Energy Build. 121 (2016) 130-138. https://doi.org/10.1016/j.enbuild.2016.03.076.

[25] L. Jia, J. Liu, C. Wang, X. Cao, Z. Zhang, Study of the thermal performance of a novel dew point evaporative cooler, Appl. Therm. Eng. 160 (2019). https://doi.org/10.1016/j.applthermaleng.2019.114069.

[26] K. Panchabikesan, K. Vellaisamy, V. Ramalingam, Passive cooling potential in buildings under various climatic conditions in India, Renew. Sustain. Energy Rev. 78 (2017) 1236-1252. https://doi.org/10.1016/j.rser.2017.05.030.

[27] U. Sajjad, N. Abbas, K. Hamid, S. Abbas, I. Hussain, S.M. Ammar, M. Sultan, H.M. Ali, M. Hussain, T. ur Rehman, C.C. Wang, A review of recent advances in indirect evaporative cooling technology, Int. Commun. Heat Mass Transf. 122 (2021). https://doi.org/10.1016/j.icheatmasstransfer.2021.105140.

[28] P.M. Cuce, S. Riffat, A state of the art review of evaporative cooling systems for building applications, Renew. Sustain. Energy Rev. $54 \quad$ (2016) 1240-1249. https://doi.org/10.1016/j.rser.2015.10.066.

[29] Y. Yang, G. Cui, C.Q. Lan, Developments in evaporative cooling and enhanced evaporative cooling - A review, Renew. Sustain. Energy Rev. 113 (2019). https://doi.org/10.1016/j.rser.2019.06.037.

[30] Y.M. Xuan, F. Xiao, X.F. Niu, X. Huang, S.W. Wang, Research and applications of evaporative cooling in China: A review (II) - Systems and equipment, Renew. Sustain. Energy Rev. 16 (2012) 3523-3534. https://doi.org/10.1016/j.rser.2012.02.030.

[31] Y.M. Xuan, F. Xiao, X.F. Niu, X. Huang, S.W. Wang, Research and application of evaporative cooling in China: A review (I) - Research, Renew. Sustain. Energy Rev. 16 (2012) 3535-3546. https://doi.org/10.1016/j.rser.2012.01.052.

[32] A.T. Mohammad, S. Bin Mat, M.Y. Sulaiman, K. Sopian, A.A. Al-Abidi, Historical review of liquid desiccant evaporation cooling technology, Energy Build. 67 (2013) 22-33. https://doi.org/10.1016/j.enbuild.2013.08.018.

[33] M.H. Mahmood, M. Sultan, T. Miyazaki, S. Koyama, V.S. Maisotsenko, Overview of the Maisotsenko cycle - A way towards dew point evaporative cooling, Renew. Sustain. Energy Rev. 66 (2016) 537-555. https://doi.org/10.1016/j.rser.2016.08.022.

[34] M.W. Shahzad, M. Burhan, D. Ybyraiymkul, S.J. Oh, K.C. Ng, An improved indirect 
evaporative cooler experimental investigation, Appl. Energy. 256 (2019) 113934. https://doi.org/10.1016/J.APENERGY.2019.113934.

[35] M.W. Shahzad, J. Lin, B. Bin Xu, L. Dala, Q. Chen, M. Burhan, M. Sultan, W. Worek, K.C. $\mathrm{Ng}$, A spatiotemporal indirect evaporative cooler enabled by transiently interceding water mist, Energy. 217 (2021) 119352. https://doi.org/10.1016/J.ENERGY.2020.119352.

[36] K.C. Ng, M.W. SHAHZAD, M. BURHAN, D. YBYRAIYMKUL, S.J. Oh, Combined direct and indirect evaporative cooling system and method, US20210341157A1, 2021.

[37] D. Pandelidis, A. Cichoń, A. Pacak, S. Anisimov, P. Drąg, Counter-flow indirect evaporative cooler for heat recovery in the temperate climate, Energy. 165 (2018) 877-894. https://doi.org/10.1016/j.energy.2018.09.123.

[38] S. Kashyap, J. Sarkar, A. Kumar, Exergy, economic, environmental and sustainability analyses of possible regenerative evaporative cooling device topologies, Build. Environ. 180 (2020). https://doi.org/10.1016/j.buildenv.2020.107033.

[39] Z. Duan, C. Zhan, X. Zhao, X. Dong, Experimental study of a counter-flow regenerative evaporative cooler, Build. Environ. $104 \quad$ (2016) 47-58. https://doi.org/10.1016/j.buildenv.2016.04.029.

[40] V.S. Majsotsenko, V.N. Frolov, A.B. Tsimerman, M.G. Zekser, Device for Indirect Evaporative Cooling of Air, SU620745A1, 1978.

[41] V.S. Majsotsenko, I.M. Pecherskaya, A.B. Tsimerman, M.G. Zekser, Unit for Indirect Evaporation Cooling of Air, SU979796A1, 1982.

[42] C. Zhan, Z. Duan, X. Zhao, S. Smith, H. Jin, S. Riffat, Comparative study of the performance of the M-cycle counter-flow and cross-flow heat exchangers for indirect evaporative cooling Paving the path toward sustainable cooling of buildings, Energy. 36 (2011) 6790-6805. https://doi.org/10.1016/j.energy.2011.10.019.

[43] R. Shirmohammadi, N. Gilani, Effectiveness enhancement and performance evaluation of indirect-direct evaporative cooling system for a wide variety of climates, Environ. Prog. Sustain. Energy. 38 (2019). https://doi.org/10.1002/ep.13032.

[44] F. Comino, M. Ruiz de Adana, F. Peci, Energy saving potential of a hybrid HVAC system with a desiccant wheel activated at low temperatures and an indirect evaporative cooler in handling air in buildings with high latent loads, Appl. Therm. Eng. 131 (2018) 412-427. https://doi.org/10.1016/j.applthermaleng.2017.12.004.

[45] X. Cui, L. Sun, S. Zhang, L. Jin, On the study of a hybrid indirect evaporative pre-cooling 
system for various climates, Energies. 12 (2019). https://doi.org/10.3390/en12234419.

[46] K. Matsui, K. Thu, T. Miyazaki, A hybrid power cycle using an inverted Brayton cycle with an indirect evaporative device for waste-heat recovery, Appl. Therm. Eng. 170 (2020). https://doi.org/10.1016/j.applthermaleng.2020.115029.

[47] Z. Duan, C. Zhan, X. Zhang, M. Mustafa, X. Zhao, B. Alimohammadisagvand, A. Hasan, Indirect evaporative cooling: Past, present and future potentials, Renew. Sustain. Energy Rev. 16 (2012) 6823-6850. https://doi.org/10.1016/j.rser.2012.07.007.

[48] ANSI/ASHRAE Standard 143-2015 - Method of Test for Rating Indirect Evaporative Coolers, (n.d.). https://webstore.ansi.org/standards/ashrae/ansiashraestandard1432015 (accessed June 23, 2021).

[49] Standards Store - GCC Standardization Organization, (n.d.). https://www.gso.org.sa/store/standards/GSO:549088/ (accessed June 12, 2021).

[50] C22.2 No.104-01 (R2006) | Standards Council of Canada - Conseil canadien des normes, (n.d.). https://www.scc.ca/en/standardsdb/standards/7614 (accessed June 12, 2021).

[51] GB/T 25860-2010 Standard english version, China National Standards, GB/T 258602010 Evaporative air cooler, (n.d.). http://www.gbstandards.org/GB_standard_english.asp?code=GB/T 25860-2010 (accessed June 12, 2021).

[52] H. Zhang, H. Ma, S. Ma, Investigation on indirect evaporative cooling system integrated with $\begin{array}{lllll}\text { liquid dehumidification, } & \text { Energy } & \text { Build. } & 249 & \text { (2021) }\end{array}$ https://doi.org/10.1016/j.enbuild.2021.111179.

[53] T. Sun, X. Huang, Y. Chen, H. Zhang, Experimental investigation of water spraying in an indirect evaporative cooler from nozzle type and spray strategy perspectives, Energy Build. 214 (2020). https://doi.org/10.1016/j.enbuild.2020.109871.

[54] Y. Liu, Y.G. Akhlaghi, X. Zhao, J. Li, Experimental and numerical investigation of a highefficiency dew-point evaporative cooler, Energy Build. 197 (2019) 120-130. https://doi.org/10.1016/j.enbuild.2019.05.038.

[55] Available from, (n.d.). https://worldwide.espacenet.com/patent/search?q=ti \%3D \%22indirect evaporative\%22 AND pd \%3D \%222020\%22 (accessed June 2, 2021).

[56] J.T. Fisher, Evaporative heat exchanger, US2990696A, 1961.

[57] M. Guilizzoni, S. Milani, P. Liberati, S. De Antonellis, Effect of plates coating on performance of an indirect evaporative cooling system, Int. J. Refrig. 104 (2019) 367-375. 
https://doi.org/10.1016/j.ijrefrig.2019.05.029.

[58] Kiyoshi Uyama, Multi-wave packing material and a device for utilizing the same, US3540702A, 1970.

[59] T.P. Carter, R.E. Cates, J.E.N.S. Richard H. Harrison, R.H.J. Harrison, N. Edward Schinner, Angularly grooved corrugated fill for water cooling tower, US4361426A, 1982.

[60] L.M. Hood, D.M. West, Multi-stage indirect-direct evaporative cooling process and apparatus, US4380910A, 1983.

[61] V.S. Maisotsenko, A.N. Gershuni, Method for indirect-evaporative air cooling, US4977753A, 1990.

[62] M. Nonna, P. Irina, T. Aleksandr, Z. Mikhail, Z. Petr, Apparatus for indirect evaporative cooling of air, SU1537970A1, 1990.

[63] P. Irina, T. Aleksandr, Z. Georgij, Z. Mikhail, Z. Petr, Regenerative indirect-evaporative aircooler, SU1562614A1, 1990.

[64] A.N. Gershuni, V.S. Maisotsenko, A.A. Kaminnik, V.K. Zaripov, A.P. Nischik, A.I. Levterov, Apparatus for indirect evaporative gas cooling, US4976113A, 1990.

[65] Y. Rotenberg, M.T. Wolfe, Apparatus \& Method for indirect evaporative cooling of a fluid, US5187946A, 1993.

[66] C. Munters, P. Norback, Method of cooling air and apparatus intended therefor, US4002040A, 1977.

[67] C.V. Nikolaevich, G.V. Nikolaevich, K.A. Petrovich, M.V. Stepanovich, M.Y. Aleksandrovich, O.G. Pavlovich, S.L. Nikolaevich, V.N. Petrovich, Indirect evaporative cooling unit, RU2046257C1, 1995.

[68] K. Sergej, K. Valerij, K. Yurij, M.A. I, M. Valentin, M.V.A. Sik, T.P. Sik, Method of indirect evaporative cooling of air in rooms and device for its realization, RU2037745C1, 1995.

[69] K. Sergej, K. Valerij, K. Yurij, M.A. I, M. Valentin, M.V.A. Sik, T.P. Sik, Air (gas) indirect evaporative cooling device, RU2140044C1, 1999.

[70] O. Hiroshi, Indirect evaporative cooling device, JP2002206834A, 2002.

[71] B.R. Brooks, D.L. Field, Indirect evaporative cooling apparatus, US6523604B1, 2003.

[72] L.E. Gillan, V. MaisotsenkoAlan, D. Gillan, R.J. Gillan, Indirect evaporative cooling of a gas using common product and working gas in a partial counter-flow configuration, WO2005090870A1, 2005. 
[73] V. Maisotsenko, L.E. Gillan, T.L. Heaton, A.D. Gillan, Method and plate apparatus for dew point evaporative cooler, US6581402B2, 2003.

[74] A.D. Gillan, L.E. Gillan, R.J. Gillan, T.L. Heaton, V. Maisotsenko, Plate heat and mass exchanger with edge extension, EP1716369B1, 2010.

[75] G. Alan, G. Leland, H. Timothy, M. Valeriy, Single and multi-stage indirect evaporative cooling method capable of repeatedly utilizing wet energy, CN100359249C, 2008.

[76] S.G. Eun, L.D. Young, Indirect evaporative cooling machine and regenerative evaporative cooling machine using the same, KR20090019326A, 2009.

[77] S. Tong, Heat pipe-type indirect evaporative cooling air conditioner, CN201377870Y, 2010.

[78] H. Xiang, M. Xiuming, W. Fang, W. Li, W. Junmei, Porous functional ceramic dew point plate fin type indirect evaporative cooler, CN101266091A, 2010.

[79] D. Yuhui, H. Xiang, M. Xiuming, W. Li, Square porous ceramic vertical tube type dew point indirect evaporative cooler, CN101329104A, 2011.

[80] Q. Zhang, Z. Liu, Countercurrent dew point indirect evaporative cooler, CN101761997A, 2013.

[81] G. Yu, L. Qi, X. Bian, Y. Zhai, Y. Zhang, Multi-channel plate-fin type dew point indirect evaporative cooling device, CN102095320A, 2013.

[82] H. Zhou, K. Fan, X. Huang, Reverse-flow dew-point indirect-direct two-stage evaporative cooler, CN102494398A, 2013.

[83] R. Gilbert, Efficiency indirect evaporative cooler, US20140183764A1, 2015.

[84] C. Xuan, L. Junhie, Countercurrent plate type dew-point indirect evaporative cooler with internal dividing structure, and channel clapboard, CN104534603A, 2017.

[85] Y. Liying, Indirect evaporative cooling core, CN103994677A, 2015.

[86] M.M. Davidovich, S.I. Mudarisovich, Indirect evaporative cooling device, WO2016022039A1, 2016.

[87] D. Chang, L. Liuji, W. Yanling, W. Xuehong, Y. Yanong, Z. Jun, Intersected direct-current dew point indirect evaporative cooler, CN105783340A, 2018.

[88] Z. Dashun, Triple channel indirect evaporation cooler, CN206531212U, 2017.

[89] C. Mingsong, H. Huaming, H. Jialin, H. Hualing, Indirect evaporative cooler, CN106595355A, 2018. 
[90] C. Zhiqi, D. Yuhui, Tubular type dew point indirect evaporative cooler, CN108362043A, 2018.

[91] L. Han, L. Jian, G. Chunmei, M. Dandong, Z. Zhimiao, Plate type indirect evaporative cooling heat exchanger, CN209783354U, 2019.

[92] W. Chengbin, Produce the indirect evaporating-cooling equipment and air-conditioning system of dew-point temperature cold wind, CN110469929A, 2019.

[93] C. Xiuqin, W. Lei, W. Yin, X. Yaohua, Z. Changhong, Z. Jianli, Tubular type dew point indirect evaporative cooling air conditioner, CN108826539A, 2020.

[94] G. Gaiying, H. Huaming, H. Jialin, Dew point indirect evaporative cooler core, CN210891996U, 2020.

[95] H. Hongxia, H. Xiang, J. Yangfan, Cross-flow dew point indirect evaporative cooler with movable water distribution, CN212108847U, 2020.

[96] C. Liwei, G. Yuping, S. Zichao, W. Xianji, W. Yucao, Z. Jiancong, Heat exchange unit, cooling core and dew point indirect evaporative cooler, CN212457244U, 2021.

[97] V. Majsotsenko, P. Vladimir, T. Aleksandr, Z. Mikhail, Device for indirect evaporative cooling of air, SU571668A1, 1977.

[98] V. Maisotsenko, L.E.G.L. Heaton, A.D. Gillan, Indirect evaporative cooling mechanism, WO2001057460A1, 2001.

[99] R.C. Bourne, D. Callaway, B.E. Lee, A two stage indirect evaporative cooling system, WO2005064257A1, 2005.

[100] N.H. Des Champs, Indirect evaporative cooling heat exchanger, WO2005119156A2, 2006.

[101] H. Xiang, J. Guiming, T. Yongjian, W. Chao, Y. Suqian, Y. Youcheng, Pipe type indirect evaporation cooling and spraying type direct evaporation cooling composite air conditioner unit, CN201187850Y, 2009.

[102] R.W. Gilbert, Indirect evaporative cooler construction, WO2010054426A1, 2010.

[103] K. Konno, Indirect evaporative cooling apparatus, CN102168929A, 2011.

[104] H. Zhang, Spray water distribution system in plate-type indirect evaporative cooling system, CN102116512A, 2011.

[105] D. Yao, S. Wu, W. Wang, X. Huang, Heat pipe indirect evaporative cooler with water absorbent materials wrapping outsides of light pipes at hot ends, CN201731786U, 2011.

[106] C. Li, T. Sun, W. Wang, X. Huang, Spray reinforcing low-finned tube indirect evaporative 
cooler, CN101818997A, 2012.

[107] H. Xiang, Z. Luyao, Z. Xin, Tube indirect evaporative cooler with water film expanding plates, CN203216313U, 2013.

[108] N.H. Deschamps, Indirect evaporative cooling heat exchanger, US20140262163A1, 2014.

[109] E. Kozubal, J. Woods, R. Judkoff, Indirect evaporative coolers with enhanced heat transfer, US9140471B2, 2015.

[110] C. Junjie, H. Xiang, S. Tiezhu, Z. Hong, A kind of countercurrent dew point indirect evaporative cools down air-conditioning, CN206771588U, 2017.

[111] J.J. Rede, J.H. Bean, System and method of a water management for an indirect evaporative cooler, US20190107332A1, 2019.

[112] J.L. Grinham, J. Alvarenga, M. Bechthold, J. Aizenberg, Hydrophobic barrier layer for ceramic indirect evaporative cooling systems, WO2020072597A1, 2020.

[113] K.S. Karnik, System and method for indirect evaporative cooling, US20200284452A1, 2020.

[114] A. Lowenstein, Dewpoint indirect evaporative cooler, US10739079B2, 2020.

[115] S.J. Slayzak, E.J. Kozubal, Indirect evaporative cooler using membrane-contained, liquid desiccant for dehumidification, EP2250446A1, 2020.

[116] K. Dinh, Indirect evaporative cooling system, US4827733A, 1989.

[117] J.D. Cass, Indirect Evaporative Cooling System, US20120047937A1, 2012.

[118] H. Xiang, L. Weihua, S. Xiaoqing, Indirect evaporative cooling air -conditioning unit of vertical high efficiency, CN204786979U, 2015.

[119] H. Xiang, L. Kailei, Y. Liran, G. Zhichao, W. Wenbo, Data center's photovoltaic dew point indirect evaporative Cooling Air-conditioning System, CN106765755A, 2019.

[120] F. Yaowei, H. Xiang, L. Chaoyang, L. Zhenyu, Q. Yueying, Photovoltaic direct-drive dew point indirect evaporative cooling air conditioning system for data center, CN110753479A, 2020.

[121] C. Jiao, C. Ke, L. Chang, L. Feng, L. Jing, M. Yiping, W. Taisheng, X. Feng, Dew-point indirect evaporative cooling device and temperature and humidity independent control air conditioning system, CN104121648A, 2017.

[122] K.H. Kun, Indirect evaporative cooling outdoor unit of thermo-hygrostat, KR101878367B1, 2018. 
[123] W. Fang, Y. Yanshun, Z. Tao, Z. Yuanyuan, The indirect evaporating-cooling system and its control method of a kind of cooling air conditioner, CN107830596A, 2018.

[124] Liu Xing, Control system of indirect evaporative cooling equipment of data center, CN210569050U, 2020.

[125] C. Meng, H. Xiang, J. Yangfan, Indirect evaporative cooling air conditioning unit using condenser and evaporator, CN111295084A, 2020.

[126] T. Yan, Secondary side parallel indirect evaporation natural cooling system of data center and control method thereof, CN111750464A, 2020.

[127] T. Gao, Control and optimization of indirect evaporative cooling units for data center cooling, US10820452B2, 2020.

[128] W. Dawei, Z. Hongyu, A kind of cold outdoor fan control method of indirect evaporation and control device, CN109827269A, 2020.

[129] C. Jinqi, J. Xu, L. Yili, L. Kangyi, L. Dongjian, M. Xiaozhuang, W. Xianying, X. Wenke, Fluorine pump energy-saving indirect evaporative cooling air conditioning unit and control method, CN111594962A, 2020.

[130] W. Dawei, Z. Hongyu, Spray control method and device for indirect evaporative cold-source cold pump, WO2020151112A1, 2020.

[131] C. Yunwei, L. Jiaotong, T. Kai, W. Gang, Machine room cooling system and indirect evaporative cooling bypass system, CN211503094U, 2020.

[132] C. Dongsheng, R. Jintao, W. Hua, Indirect evaporative cooler and control method, CN112268326A, 2021.

[133] L. Zhengjie, T. Weiwei, Intelligent energy efficiency control system and intelligent energy efficiency control method for indirect evaporative cooling unit, CN112228982A, 2021. 
Highlights:

1. Patents of indirect evaporative coolers are reviewed.

2. Research gaps are identified, and the outlook of this technology is highlighted.

3. More patents design and optimized heat exchanger for indirect evaporative coolers.

4. Counter-flow configuration provided more cooling and system compactness. 


\section{Declaration of interests}

$\bigotimes$ The authors declare that they have no known competing financial interests or personal relationships that could have appeared to influence the work reported in this paper.

$\square$ The authors declare the following financial interests/personal relationships which may be considered as potential competing interests: 